\title{
State of Art Technology: Synthesis of Carbon Dots and Their Potential Applications in Biomedical, Research and Environ- mental Remediation
}

\author{
Areeba Khayal ${ }^{1 *}$, Vinars Dawane ${ }^{2}$, Virendra Kumar Yadav ${ }^{3, *}$, Krishna Kumar Yadav ${ }^{4}$, Samreen Heena Khan ${ }^{3}$ \\ 1 Department of Chemistry, Aligarh Muslim University, Aligarh 202002, India \\ 2 School of Environment and Sustainable Development, Central University of Gujarat, Gandhinagar 382030 \\ India; vinars27dawane2009@gmail.com (V.D.) \\ 3 Research and Development Centre, YNC ENVIS Pvt. Limited, New Delhi, 110059, India; \\ samreen.heena.khan@gmail.com (S.H.K.) \\ 4 Faculty of Science and Technology, Madhyanchal Professional University, Ratibad, Bhopal, 462044, India; \\ envirokrishna@gmail.com ; (K.K.Y.) \\ * Correspondence: author: areebakhayal12@gmail.com (A.K.); virendra.yadav@jnujaipur.ac.in (V.K.Y);
}

\begin{abstract}
Cutting-edge technologies are intensifying into new skylines and this remarkable progress has been successfully influenced by the tiny level engineering of carbon dots technology, their synthesis advancement and impressive applications in the field of allied sciences. The advances of science and its conjugation with interdisciplinary fields emerged in carbon dots making, their controlled characterization and applications into faster, cheaper as well as more reliable products in various scientific domains. Thus, a new era in nanotechnology has developed into carbon dots technology. The understanding of the generation process, control on making processes and selected applications of carbon dots such as energy storage, environmental monitoring, catalysis, contaminates detections and complex environmental forensics, drug delivery, drug targeting and other biomedical applications etc. are among the most promising applications of carbon dots and thus a thrust area of research today. In this regard, various types of carbon dots nanomaterials such as oxides, their composites and conjugations etc. have been flocking significant attention due to their remarkable potential in this thrust area of energy, the environment and technology. Thus, the present paper highlights the role and importance of carbon dots, recent advancements in their synthesis methods, properties and emerging applications.
\end{abstract}

Keywords: carbon dots; electrochemical synthesis; energy storage; nanotechnology; graphene

\section{Introduction}

Nanotechnology has played an immense role in each and every field of the sciences whether in medicine [1,2], research or environmental cleanup. No doubt, nanotechnology and NPs have played none other than a second role in the 21st century. All these areas of science have widely exploited the metal and metal oxide nanoparticles, but such NPs have numerous drawbacks such as their non-biodegradable nature, toxicity etc. When such NPs are surface functionalized then their acceptance increases and manifolds in various field. In medicine, NPs, with altered biophysical attributes, are being used to make incredibly spreadable, biocompatible nano pharmaceuticals with lower immunity and greater protection, including enhanced solubility $[3,4]$.

Since ancient times, several metallic and nonmetallic particles have been used to control the growth of microorganisms, especially in agricultural fields to protect the crop from various bacterial and fungal diseases. Meanwhile, pesticides and insecticides were also used very frequently, which lead to the toxicity for human beings. Insecticides are often used to combat plant diseases, while constant use always creates serious environmental 
problems. So far, much effort has gone into the development of antibiotics, drugs and antibacterial ingredients. A large number of nanoparticles (for example, cationic conjugated polymers, dehydrogel peptides, semiconductors, noble metal particles, graphene layers with carbon tubes, graphene oxide and element doped carbon nanoparticles) have been used, increasing the permeability of bacterial membranes and conventional in comparison with antibiotics [5]. Such antibacterial nanomaterials are still rich in microbial resistance and particle deterioration [6], resulting in a slew of alternative pathogens or even risks.

In constantly degrading nanomaterials, they could impact the taxonomic category affiliated with the analysis in a defined $\mathrm{N}_{2}$ ecosystem, methane oxidation and complex decomposition by modifying the proportion of microbial groups in a therapeutic dose [7]. It would be desirable to develop biologically safe and biodegradable nanomaterials with various antibacterial properties. So, there was a need for biocompatible and less toxic materials for this application, and carbon dots were found to be most suitable.

So, carbon particles especially carbon nanomaterials [8] have gained a huge attention, not only due to their biodegradable and less toxic nature, but also due to their easy surface functionalization. Recently, carbon dots (CD) have been optimistic, plentiful, low-cost [9] and have steadily become the performer throughout the Nano Carbon Dot community, prompting comprehensive research owing to the high opportunity for a variety of technological implementations [10]. Carbon quantum dots (CQDs) are a novel fluorescent nanostructure comprised of a carbon network formed via an indistinct carbon framework. Such particles have low toxicity, strong fluorescence, tunable color emission, easy to surface functionalization, low cost and high aqueous stability and photostability [11]. Various approaches have been used to synthesize CQDs such as (i) top-down pathways, such as the laser ablation technique [1,2], electrochemical exfoliation (ECE) [13] and the chemical oxidation method (destruction of large carbon materials) [14], or (ii) bottom-up pathways (small precursor composition): microwave associated synthesis [15], plasma [16], hydrothermal and solvothermal treatments [17]. CQD has been recorded to reduce antimicrobial properties and potency based on the scale including charge density, which could be conveniently regulated by surface modification (for example - $\mathrm{COOH},-\mathrm{OH}$, amino, epoxy, $\mathrm{NH}_{2}$, etc.) [17]. CQD causes disintegration of the membrane as well as the generation of reactive oxygen species (ROS); both are suitable research of antimicrobial action [18]. Enhanced ROS levels and oxidative exposure alter genetic material as well as the protein shape, and CQD is compatible with graphene oxide, single-wall carbon nanotubes, and fullerenes, although it is seldom reported with other carbon nanostructures [5]. Carbon nanomaterials' antimicrobial effects [19] have been thoroughly researched, and further comprehensive research is required to clarify the interaction between surface chemistry, CQD and bactericidal effects [20]. Meanwhile fluorescent carbon (CD) dots with size parameters, water solubility, lightfastness, especially high levels of biocompatibility, and low toxicity, have generated worldwide interest in such disciplines bioimaging, analysis and gene therapy [20]. According to such properties, this new kind of nanoparticle (NP) outperforms quantum dots (high toxicity problems) [21] and conventional dyes (photobleaching) [22]. The most recent application of CDs is in the field of chemical warfare agents, especially for the detection of hazardous chemicals. These CDs were used either functionalized and non-surface modified forms which was reported by Kumar et al., Paul et al., Tuccitto et al., Tuccitto et al., Tuccitto et al. and Butero et al. [23-28].

The current review work highlights the various synthesis approaches and their applications in fields such as chemical warfare agents, medicine, environmental clean-up, etc. The objective of this study is to provide state-of-the-art research, in the synthesis and applications of carbon dots in recent years.

\section{Synthesis of Carbon Dots}

Carbon dots (CDs) are similar to quantum dots, where the source of precursor material is mainly carbon in the case of carbon dots, whereas the sources of quantum dots are metal oxides, metal sulfide etc. QDs are sometimes known "artificial atoms", which are 
actually nanocrystals with very small sizes. They have acquired the name "artificial atoms" due to the possession of quantum effects similar to conventional atoms, which are conjugated with the fact that they are "tailor-made materials" [29]. CDs can be classified into three basic types: graphene quantum dots, carbon quantum dots and carbonized polymer dots.

Top-down and bottom-up synthetic approaches to C-dots seem to be the most prominent. Laser ablation (LA), arc discharge (AcD), electrochemical techniques and plasma treatment are all forms of top-down methods for cutting carbon materials using carbon nanomaterials [30]. Pyrolytic processes, template methods, supported synthetic strategies microwave-based methods, chemical oxidation, reverse micelle processes and others are instances of bottom-up methodologies [31]. All these top-down and bottom-up approaches for the synthesis of $\mathrm{C}$-dots are shown below in Figure 1. Top-down approaches for manufacturing C-dots are shown in Figure 2.

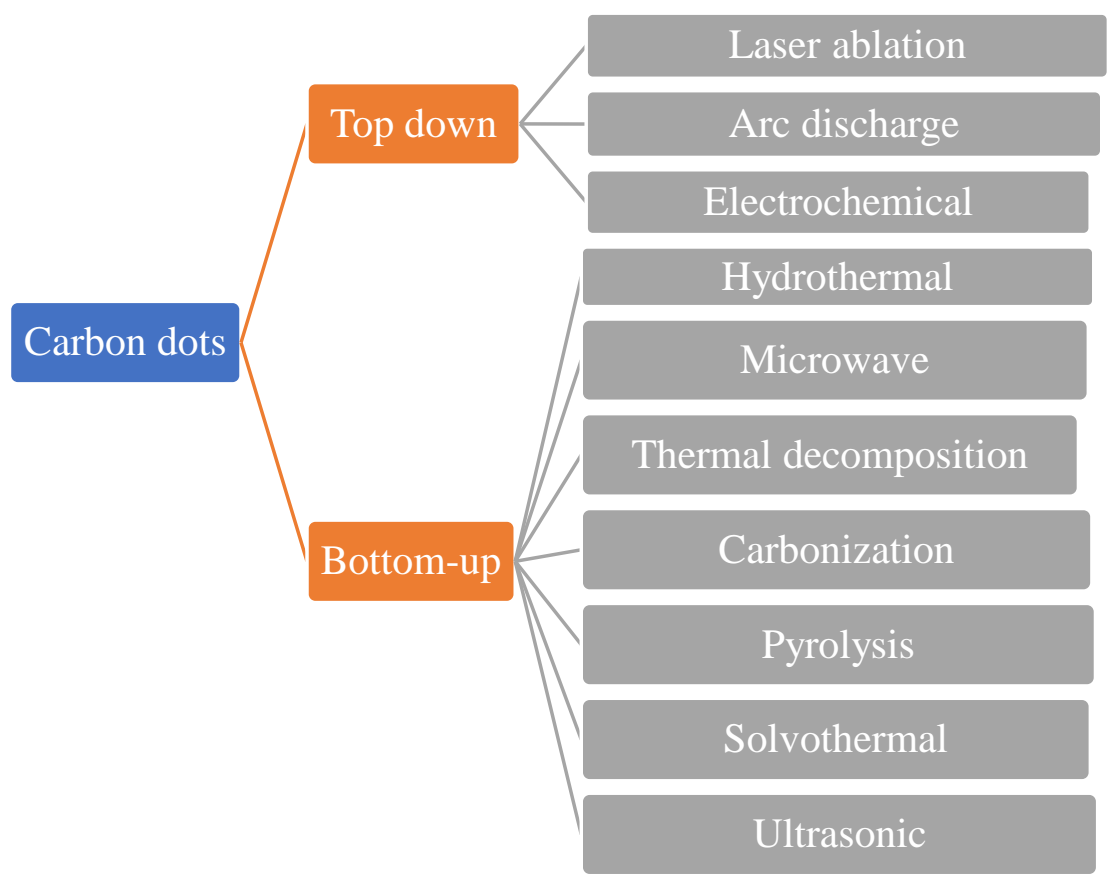

Figure 1. Different methods for the synthesis of carbon dots. 


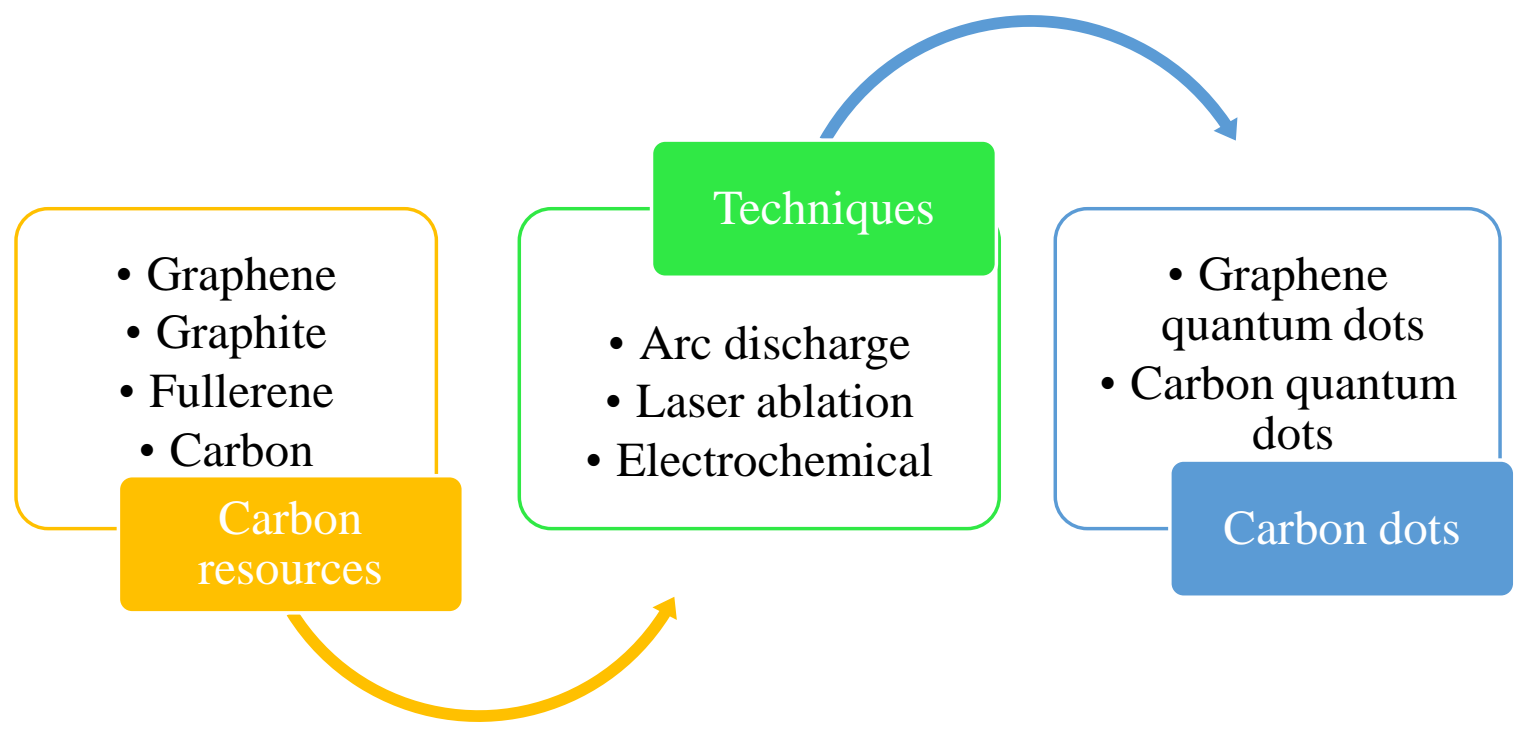

Figure 2. Top-down approach for the synthesis of carbon dots.

\subsection{Laser Ablation (LA)}

LA is a synthetic method that involves the use of a laser and a carbon source for the synthesis of carbon dots. Sun et al., used a method to generate fluorescence C-dot, where they firstly mixed graphite powder and cement and then heat-treated it to obtain a carbon source. Furthermore, by using a laser source carbon was removed from the surface by using an argon gas vapor stream at $900{ }^{\circ} \mathrm{C}$ and $75 \mathrm{kPa}$ to obtain carbon nanoparticles (CNPs) [32]. Such synthesized CNP sizes were variable, which exhibited no photoluminescence (PL). The sample was then treated with polyethylene glycol (PEG1500N) or poly (propionyl ethylene-imine-ethyleneimine) after being refluxed in aqueous nitric acid over $12 \mathrm{~h}$ (PPEI-EI). The PL of passivated C-dots with a diameter at about $5 \mathrm{~nm}$ was very powerful, whose fluorescence quantum yields ranged from $\sim 4 \%$ to $10 \%$ at $400 \mathrm{~nm}$ excitation [33-35].

Likewise, Gonsalves et al., produced carbon nanoparticles by embolization immediately from a carbon target dissolved in non-ionized liquid; the carbon particles that resulted would not fluoresce [36]. The carbon nanomaterials were deposited in aqueous nitric acid and then allowed to stand for $12 \mathrm{~h}$ to enable the carbon nanoparticles' surface, after which PEG200 was applied to the mixture and boiled under reflux for $28 \mathrm{~h}$, followed by mercapto-succinic acid and warmed for $31 \mathrm{~h}$. Then, the colorless mixture turned to light brown, fluorescent C-dots via a size distribution of $267 \mathrm{~nm}$. The scale of the poly ethyl glycol (PEG) chain as well as the existence of other parameters have no impact on the long-term destruction of the activated $\mathrm{C}$-dot. Iodide reduces the fluorescence strength of the C-dot; however, other metals including $\mathrm{Hg}^{2+}, \mathrm{Ca}^{2+}, \mathrm{Ni}^{2+}, \mathrm{Zn}^{2+}, \mathrm{Cd}^{2+}, \mathrm{Zn}^{2+}$ and $\mathrm{Cu}^{2+}$ ions disperse. Therefore, it has no impact on the fluorescence of C-dots, so it could be employed to monitor iodine [36].

By dispersing ultrasonic laser radiation throughout a PEG1500N mixture over $4 \mathrm{~h}$, a uniform black suspension has been produced. C-dots were achieved from a color precipitate following centrifugation (5000 rpm). The average thickness of the C-dot microstructure could affect quantum fluorescence performance, which could be regulated by changing the pulse width of a laser pulse [37]. Laser ablation has a number of advantages, including ease of use and the ability to produce a variety of nanostructures. However, in order to meet the carbon mark, this approach necessitates a large amount of carbon materials [38]. Carbon nanostructures produced by laser radiation have a wide range of sizes, 
and large particles could be conveniently separated by centrifugation, which leads to effective utilization of carbon nanoparticles and carbon materials [39]. Calabro et al., synthesized carbon quantum dots and did a comparative analysis. They used a one-step pulse ablation process and a chemical oxidation of carbon nano-onions to make graphene quantum dots. The authors compared the photoluminescence spectra of both quantum dots and concluded that the laser ablation model seemed to have a blue shifted emission compared to the chemical oxidation one that they referred to in the particles scale and surface functional group impact. The authors also emphasized that the laser ablation process product had a stronger decreased thickness and an estimated diameter of single coated about $1.8(6) \mathrm{nm}$, whereas the chemical oxidation product had an approximate dimension of 4.1(8) $\mathrm{nm}$ and a thickness compared to 2-3 graphene layers. Authors also elaborated functional group preferences as well as the carbon friction phenomenon which was different for both cases, such as the fact that the oxidation of chemical quantum dots favored carboxylic categories or a larger $\mathrm{sp}^{2}$ carbon content although laser ablation quantum dots supported hydroxyl categories as well as a larger $\mathrm{sp}^{3}$ carbon content. The authors used the PL longevity observations to demonstrate important insides in the radiative as well as non-radiative decay pathways of the functional groups (FG) at the surface and $\mathrm{sp}^{2}$ carbon domains, which were reported to be 7.9(6) ns for emission by - $\mathrm{COOH}$ categories and $3.18(10)$ ns for emission by hydroxyl categories, accordingly. In comparison to chemical oxidation, the authors concluded that liquid form laser ablation produces quantum dots in a much faster and safer one-step procedure with fewer initial chemicals and residues $[40,41]$. The various studies carried out for the synthesis of C-dots by laser ablation technique are given below in Table 1 .

Table 1. Laser ablation-based synthesis of carbon dots.

\begin{tabular}{|c|c|c|c|c|}
\hline $\begin{array}{c}\text { Source material of } \\
\text { carbon }\end{array}$ & Size of C-dots & Morphology & Applications & References \\
\hline $\begin{array}{l}\text { Graphite in } \\
\text { Polyethylenimine } \\
\text { and }\end{array}$ & $\begin{array}{c}\text { a fairly spherical } \\
\text { shape with } \\
\text { diameters from } 1 \text { to }\end{array}$ & & $\begin{array}{c}\text { Luminescent CD } \\
\text { material for } \\
\text { various }\end{array}$ & [42] \\
\hline Ethylenediamine & $3 \mathrm{~nm}$ & & applications & \\
\hline $\begin{array}{l}\text { Graphite target } \\
\text { irradiation }\end{array}$ & $2-3 \mathrm{~nm}$ & & $\begin{array}{c}\text { Various potential } \\
\text { associated } \\
\text { applications } \\
\end{array}$ & [43] \\
\hline $\begin{array}{c}\text { C-dots NPs } \\
\text { functionalized with } \\
\text { PEG200 and N- } \\
\text { acetyl-1-cysteine }\end{array}$ & $\begin{array}{c}\text { Thin (about } 750 \\
\mathrm{~nm} \text { ), homogenous } \\
\text { and smooth } \\
\text { (roughness of } 2.7 \pm \\
0.7 \AA \text { ) film }\end{array}$ & & $\begin{array}{l}\text { sensor for } \mathrm{Hg}(\mathrm{II}) \\
\text { ions }\end{array}$ & {$[44]$} \\
\hline Graphite powders & $\begin{array}{l}\text { Ultra small size } 1 \\
\text { nm }\end{array}$ & & $\begin{array}{l}\text { Sensing and } \\
\text { catalytic } \\
\text { applications }\end{array}$ & {$[45]$} \\
\hline Graphite & $\begin{array}{c}\text { Flower-like } \\
\text { morphology of the } \\
\text { particles with a } \\
\text { broad size } \\
\text { distribution ranging } \\
\text { from } 200-500 \mathrm{~nm} \text {. }\end{array}$ & & $\begin{array}{c}\text { Photoluminescen } \\
\text { ce ability related } \\
\text { applications }\end{array}$ & [46] \\
\hline $\begin{array}{c}\text { Mercapto-succinic } \\
\text { acid }\end{array}$ & & & & {$[47]$} \\
\hline Carbon solid & $\begin{array}{l}\text { Induced in acetone } \\
\text { with laser pulses of }\end{array}$ & $\begin{array}{c}\text { Close-spherical } \\
\text { amorphous } \\
\text { CNDs with }\end{array}$ & $\begin{array}{l}\text { Light emitting } \\
\text { purposes }\end{array}$ & {$[48]$} \\
\hline
\end{tabular}




\subsection{Arc Discharge $(A c D)$}

$\mathrm{Xu}$ and colleagues oxidized AD soot using 3.3 M nitric acid to introduce the $-\mathrm{COOH}$ group, after that extracted the chamber with the $\mathrm{NaOH}$ method of producing a strong black slurry [47]. The fast-moving band is distinguished from C-dots, which seem to be extremely fluorescent and have an approximate dimension of around $18 \mathrm{~nm}$ during gel electrophoresis [49]. Bottini et al., used the electronic flash method to isolate PL nanomaterials from clean and nitric acid oxidized carbon nanostructures [50,51]. The hydrophobic, narrow-spreading carbon nanotube luminescent nanomaterials appeared impeccable. When oxidized carbon tubes were distributed in water, fluorescent nanomaterials could accumulate. Arc discharge created a very small amount of carbon nanomaterials. $\mathrm{AcD}$ dust often includes a number of complicated materials that are hard to extract. The various studies carried out for the synthesis of $\mathrm{C}$-dots by the arc discharge technique are given below in Table 2 .

Table 2. Arc discharge-based approaches for the synthesis of C-dots.

\begin{tabular}{cccc}
\hline $\begin{array}{c}\text { Source material of } \\
\text { carbon }\end{array}$ & Size/shape of C-dots & Applications & References \\
\hline Carbon by-products & Optoelectronic applications & {$[52]$} \\
\hline $\begin{array}{c}\mathrm{TiO}_{2} \text { nanostructures } \\
\text { coupled with carbon } \\
\text { dots }\end{array}$ & $\begin{array}{c}\text { Spherical shaped with } \\
\text { an average size of } 27 \\
\text { nm }\end{array}$ & $\begin{array}{c}\text { Potential optical sensing } \\
\text { applications }\end{array}$ & {$[53]$} \\
\hline $\begin{array}{c}\text { Boron doped } \\
\text { graphene quantum } \\
\text { dots }\end{array}$ & $\begin{array}{c}\text { Zero-dimensional } \\
\text { graphene quantum } \\
\text { dots (GQDs) }\end{array}$ & $\begin{array}{c}\text { Potential Luminescence and } \\
\text { optical applications }\end{array}$ & {$[54]$} \\
\hline $\begin{array}{c}\text { CNTs and Oxidized } \\
\text { CNTs }\end{array}$ & & & {$[50]$} \\
\hline
\end{tabular}

\subsection{Electrochemical Approach}

Lou et al., used a $2 \mathrm{~cm}$-distance between a high-purity graphite rod including strongly focused pyrolytic graphite, as well as a platinum $(\mathrm{Pt})$ wire as an anode and a counter-electrode [55]. After that, immerse it in a liquid/water ionic mixture then assign persistent ability to encourage the carbon content to peel away. The peeling procedure is comprised of a diverse relationship between anionic fluid inserted and anodized water isolation filter isolation and ultracentrifugation, which were being used to acquire $6 \mathrm{~nm}$ scale C-dots at $15,000 \mathrm{rpm}$ at $20^{\circ} \mathrm{C}$ from water poured over the exfoliation compounds including ethanol prior to $\mathrm{pH}$ neutralization; fluorescent quantity yield was about 2.8-5.2 percent. In the study by Yao et al., in the center, a pure graphite loop electrode as well as a titanium tube cathode were assembled [56].

An insulative O-ring had separated the anode and the cathode and electrolyte were made of pure water. Electronic voltage and ultrasonic control were used; therefore, bright blue fluorescent C-dots were widely utilized in distilled water with no need for complicated cleansing. The scale of the synthesized C-dots was around 2-3 nm, as well as the quantity yield which was $8.9 \%$. In the aqueous phase, the C-dots provided excellent fluorescent characteristics as well as thermodynamic consistency [56]. Naik et al., synthesized nitrogen doped carbon dots by using the hydrothermal process and made a decent naked eye fluorescence probe for dopamine sensing [57]. They got a linear range of $2-20 \mu \mathrm{g} / \mathrm{mL}$ along with a detection limit as low as $1.97 \mu \mathrm{g} / \mathrm{mL}$. Qin et al., used a one-step hydrothermal synthesis method for the preparation of novel carbon dots from Escherichia coli BW25113 (WT), which were found to be more useful in microbial imaging [58]. The synthesized carbon dots were found to be applicable in live as well as dead microbial imaging along with significant attributes such as biocompatibility, excellent penetrability and nontoxic 
characteristics as fluorescent probes in both in vitro and in vivo microbial imaging applications. Edison et al., used a hydrothermal synthesis process to create a nitrogen rich blue, fluorescent carbon dot (NR-CDs). They used citric acid monohydrate (CA) and 2-aminopyridine (2-AP) in this process of hydrothermal treatment [59].

Zhang et al., used one pot hydrothermal synthesis for dual emission carbon dot preparation. During this hydrothermal treatment they used sodium citrate (SC), triethylenetetramine (TETA) and rose Bengal (RB) as raw materials. In the typical synthesis, the hydrothermal environment not only helped sodium citrate and TETA to form an amide bond polymer similar to the intermediate but also initiated the halogen atom removal of the RB molecule that finally built a skeleton structure of the network intermediate. Further dehydration and carbonization resulted in the dual-emission characteristics [60],[61]. Several studies carried out for the synthesis of C-dots by the electrochemical technique are given below in Table 3.

Table 3. Electrochemical-based methods for the synthesis of C-dots.

\begin{tabular}{|c|c|c|c|}
\hline Source material of carbon & Morphology of C-dots & Applications & References \\
\hline $\begin{array}{l}\text { Sodium citrate and urea } \\
\text { (by electrochemical carbonization) }\end{array}$ & $\begin{array}{l}\text { Varies from 1.0-3.5 } \mathrm{nm} \text { and an } \\
\text { average size of } 2.4 \mathrm{~nm} \\
\text { (water soluble, fluorescent) }\end{array}$ & $\begin{array}{l}\text { Sensing application of } \mathrm{Hg}^{2+} \\
\text { determination in real samples }\end{array}$ & [62] \\
\hline $\begin{array}{c}\text { Orange juice + in ethanol and after } \\
\text { of dichloromethane }\end{array}$ & Small sized power preparation & $\begin{array}{c}\text { Detection of neurotransmitters, } \\
\text { using nontoxic reagents }\end{array}$ & [63] \\
\hline MWCNTs in propylene carbonate & $\begin{array}{c}\text { Green luminescent, (GQDs) } \\
\text { with a uniform size of } 3,5 \text {, and } \\
8.2( \pm 0.3) \mathrm{nm}\end{array}$ & $\begin{array}{l}\text { biomarkers, nanoelectronic } \\
\text { devices and chemosensors }\end{array}$ & [64] \\
\hline $\begin{array}{l}\text { A carbon dots (CDs) and chitosan } \\
\text { (CS) composite film modified } \\
\text { glassy carbon electrode }\end{array}$ & $\begin{array}{l}\text { A fine power for electrode } \\
\text { coating for composite } \\
\text { formation }\end{array}$ & biosensing of dopamine & [65] \\
\hline $\begin{array}{l}\mathrm{HAuCl}_{4} \text { into carbon nanodots } \\
\text { solution }\end{array}$ & $\begin{array}{c}\text { Composite containing } \\
\mathrm{Au} / \text { Carbon dot } \mathrm{NC} \text {, graphene } \\
\text { and a ferrocene derivative }\end{array}$ & $\begin{array}{l}\text { Sensing and detection of } \\
\text { ascorbic acid, dopamine, uric } \\
\text { acid and acetaminophen }\end{array}$ & [66] \\
\hline $\begin{array}{c}\mathrm{Fe}_{3} \mathrm{O}_{4} @ \mathrm{MnO}_{2} \text { and } \mathrm{N} \text {-doped carbon } \\
\text { dots (NCDs). }\end{array}$ & $\begin{array}{c}\text { Powdered fluorescence } \\
\text { quencher and electrochemical } \\
\text { enhancer material }\end{array}$ & $\begin{array}{l}\text { determination of hydrogen } \\
\text { peroxide }\end{array}$ & [67] \\
\hline
\end{tabular}

\subsection{Microwave Assisted Synthesis}

Microwave-assisted synthesis is a simple and cost-effective process for synthesizing CDs by irradiating electromagnetic radiation with wavelengths ranging from $1 \mathrm{~mm}$ to 1 $\mathrm{m}$ by the reaction mixture of the precursor molecules [68]. Zhu et al. used first-time microwave irradiation to made fluorescent CDs with a size of $\sim 3.7 \mathrm{~nm}$. They heated saccharides and polyethylene glycol aqueous solution in a domestic microwave oven (500 W) for almost $3 \mathrm{~min}[69,70]$. Liu et al., used glycerol as the synthesized multicolor photoluminescence CDs with an average size of $\sim 5 \mathrm{~nm}$ carbon source and as passivating agent 4,7 , 10-trioxa-1,13-tridecanediamine (TTDDA) [71,72]. Wang et al., made water-soluble CDs with pyrolysis of citric acid assisted by a single-step microwave. They both used tryptophan (Tarp) as a passivating agent and as a source of nitrogen. They heated the aqueous solution of citrate and L-Tarp for $3 \mathrm{~min}$ in a microwave oven $(700 \mathrm{~W})$ and removed the large particles at 10,000 rpm by centrifugation to get CDs of $\sim 2.6 \mathrm{~nm}$ [73]. Kiran et al., utilized citric acid as a carbon source and boronic acid with 3-aminophenyl as a passivation agent for CD manufacture [72,74]. In a microwave oven $(1200 \mathrm{~W})$, they heated the aqueous solution of citric acid and 3-aminophenyl boronic acid for $4 \mathrm{~min}$ and the average diameter of the CDs achieved ranged from 2 to $5 \mathrm{~nm}$. Cao et al., recently reported CDs from aqueous glucose and arginine solution using microwave-assisted pyrolysis in a microwave oven $(700 \mathrm{~W})$ for approximately $10 \mathrm{~min}$. The mean, as obtained, and the diameter of the $\mathrm{CD}$ was between 1 and $7 \mathrm{~nm}$. Furthermore, several other researchers published on 
the microwave-assisted CD synthesis [75]. Several studies carried out for the synthesis of C-dots by microwave assisted technique are given below in Table 4 .

Table 4. Microwave assisted synthesis of C-dots.

\begin{tabular}{|c|c|c|c|}
\hline Source material of carbon & Size/shape of C-dots & Applications & References \\
\hline $\begin{array}{l}\text { Sucrose as } C \text { source, and diethylene } \\
\text { glycol (DEG) as the reaction medium }\end{array}$ & $\begin{array}{c}\text { Water dispersive and } \\
\text { transparent with average } \\
\text { diameter about } 5 \mathrm{~nm}\end{array}$ & Optical nanoprobing & [76] \\
\hline $\begin{array}{l}\text { Chitosan }(1 \%) \text { solution }+ \text { acetic acid }(1 \%) \\
\text { solution, addition of } \mathrm{CDs} \text { to obtain } \\
\text { carbon dots-chitosan }(\mathrm{CD}-\mathrm{CH}) \\
\text { composite. }\end{array}$ & $\begin{array}{l}\text { A thin film of } \mathrm{CD}-\mathrm{CH} \\
\text { composite was prepared onto } \\
\text { ITO glass substrate }\end{array}$ & Sensing of vitamin $\mathrm{D}_{2}$ & [77] \\
\hline $\begin{array}{c}\mathrm{N} \text {-phosphonomethyl aminodiacetic acid } \\
\text { and ethylenediamine } \\
\text { (thermolysis + microwave) }\end{array}$ & $\begin{array}{l}\text { uniform dispersion with the } \\
\text { average size of } 3.3 \mathrm{~nm}\end{array}$ & Cellular imaging & [78] \\
\hline Citric acid, urea, and thiourea & $\sim 10 \mathrm{~nm}$ & $\begin{array}{l}\text { detection of } \mathrm{Hg}^{2+} \text { and } \mathrm{I} \text { - in } \\
\text { tap, river and mineral waters } \\
\text { and fish samples }\end{array}$ & [79] \\
\hline $\begin{array}{l}\text { Cystine as source for } \mathrm{C}, \mathrm{N} \text { and } \mathrm{S} \text { and } \\
\text { glycerol as the reaction solvent }\end{array}$ & Fine sized powder & $\begin{array}{l}\text { detecting } \mathrm{Hg}(\mathrm{II}) \text { in spiked } \\
\text { tap and lake waters }\end{array}$ & [80] \\
\hline $\begin{array}{c}\text { From lactose by microwave assisted } \\
\text { hydrochloric acid }\end{array}$ & $\begin{array}{c}\text { average size } 10 \mathrm{~nm} \\
\text { (fluorescent water soluble } \\
\text { carbon dots }(\mathrm{CDs}) \text { ) }\end{array}$ & $\begin{array}{l}\text { analysis of various } \\
\text { heterocyclic aromatic amines }\end{array}$ & [81] \\
\hline $\begin{array}{c}\text { Citric acid was used and glutathione or } \\
\text { thiourea as precursors of doping } \\
\text { elements. }\end{array}$ & Simple fine powder & $\begin{array}{l}\text { Mercury in river water and } \\
\text { wastewater }\end{array}$ & [82] \\
\hline $\begin{array}{l}\text { Kelp (algae) as main carbon source and } \\
\text { ethylenediamine as nitrogen dopant }\end{array}$ & Below $10 \mathrm{~nm}$ & $\begin{array}{l}\text { Detection of } \mathrm{Co}^{2+} \text { based on } \\
\text { fluorescence quenching }\end{array}$ & [83] \\
\hline
\end{tabular}

\subsection{Thermal Decomposition}

The thermal decomposition technique has also been used by researchers as another traditional bottom-up approach to synthesize CDs. A material or compound is chemically decomposed in ordinary thermal decomposition by heat action. The thermal reactions to decomposition are typically endothermic [17]. Either this type of decomposition reaction is irreversible (decomposition of Starch, protein) or reversible (ammonium chloride decomposition, calcium carbonate). The advantages of this method include ease of use, less time taking, cheap price and large-scale manufacturing [84].

Wang et al., reported highly luminescent $C D$ s as the passivation agent by the thermal decomposition of citric acid as the source of carbon and organ silane, $\mathrm{N}$ - $(\beta$-aminoethyl)$\gamma$-aminopropyl methyl dimethoxysilane (AEAPMS) [85]. They only heated the reaction mixture for $1 \mathrm{~min}$ at $240{ }^{\circ} \mathrm{C}$ and the observed $\mathrm{CD}$ diameter was $\sim 0.9 \mathrm{~nm}$. Wang et al., after that, produced the $\mathrm{CDs}$ from citric acid by using this method. They heated citric acid for $30 \mathrm{~min}$ on a hot plate at $200{ }^{\circ} \mathrm{C}$; neutralized it with a solution of sodium hydroxide and solubilized it finally for purification. The size of CDs within the 0.7 to $1 \mathrm{~nm}$ range was observed. These CDs demonstrate both independent photoluminescent (PL) and excitation-dependent properties. As well as differing QY depending on different conditions for synthesis. Wan et al. used the decomposition thermal of 1-butyl 3-methyl bromide imidazolium and l-cysteine for CD fabrication at $240{ }^{\circ} \mathrm{C}$. The AFM study showed that the height of the CDs ranged between 1.0 and $3.5 \mathrm{~nm}$. Several other studies also found this method for determination of CDs from small organic molecules [85]. Several studies carried out for the synthesis of C-dots by thermal decomposition technique are given below in Table 5. 
Table 5. Thermal decomposition-based synthesis of C-dots.

\begin{tabular}{|c|c|c|c|c|}
\hline Source material of carbon & Synthesis conditions & Size/ shape of C-dots & applications & References \\
\hline $\begin{array}{l}\text { Ascorbic acid (AA) and } \\
\text { uric acid (UA) }\end{array}$ & $\begin{array}{l}\text { Electrochemical } \\
\text { method }\end{array}$ & $\begin{array}{l}\text { Fine carbon fiber } \\
\text { electrode }\end{array}$ & $\begin{array}{c}\text { highly sensitive and } \\
\text { selective dopamine (DA) } \\
\text { detection }\end{array}$ & [86] \\
\hline $\begin{array}{c}\text { Carbon dots (CDs)/g- } \\
\text { C3N4/ZnO nanocomposite }\end{array}$ & $\begin{array}{l}\text { facile impregnation- } \\
\text { thermal method }\end{array}$ & $\begin{array}{l}\text { Composite by using } \\
\text { impregnation-thermal } \\
\text { method }\end{array}$ & $\begin{array}{l}\text { Tetracycline } \\
\text { photocatalysis in the } \\
\text { water environment }\end{array}$ & [87] \\
\hline $\begin{array}{l}\text { Citric acid monohydrate, } \\
\text { as carbon precursor } \\
\text { solid-phase composite of } \\
\text { CDs deposited on } \\
\text { Graphene }\end{array}$ & $\begin{array}{l}\text { Carbonization+ } \\
\text { microwave }\end{array}$ & $\begin{array}{c}\text { CD-graphene interaction } \\
\text { based nanomaterial } \\
1-10 \mathrm{~nm}\end{array}$ & $\begin{array}{l}\text { Light conversation } \\
\text { applications }\end{array}$ & [88] \\
\hline $\begin{array}{c}\text { Gadolinium-doped carbon } \\
\text { dots (Gd-doped CDs) }\end{array}$ & & $\begin{array}{c}\sim 18 \mathrm{~nm} \text { with } \\
\text { dispersibility in water }\end{array}$ & $\begin{array}{l}\text { MRI-guided radiotherapy } \\
\text { of tumors }\end{array}$ & [89] \\
\hline Citric acid & $240^{\circ} \mathrm{C}$ for only $1 \mathrm{~min}$ & $\sim 0.9 \mathrm{~nm}$ & & [90] \\
\hline Citric acid & $200{ }^{\circ} \mathrm{C}$ for $30 \mathrm{~min}$ & $0.7-1 \mathrm{~nm}$ & & [91] \\
\hline $\begin{array}{c}\text { 1-butyl 3-methyl } \\
\text { imidazolium bromide and } \\
\text { L-cysteine }\end{array}$ & $240^{\circ} \mathrm{C}$ & $1.0-3.5 \mathrm{~nm}$ & & [92] \\
\hline $\begin{array}{l}\text { Citric acid and } \\
\text { dicyandiamide }\end{array}$ & & Spherical shaped & & [93] \\
\hline
\end{tabular}

\subsection{Carbonization Synthesis}

Various precursor molecules can be carbonized easily; thus, this is one of the cheapest, recognized, convenient and superfast single-step technique for CD manufacturing. Carbonization is a chemical process wherein, through continuous pyrolysis in an inert environment, solid materials with higher carbon content are formed from organic materials. Wei et al., used this superfast carbonization technique to produce N-doped CDs. They used a much faster ( 2 min only) method than glucose and ethylene-dia-amine as a source for carbon and nitrogen, respectively [94]. The scale of the prepared carbon dot was observed was between 1 and $7 \mathrm{~nm}$, along with $48 \%$ of QY. In a very remarkable work, Wang et al., produced blue luminescent producing carbon dots that were thermally reduced along with a 4.8 to $9 \mathrm{~nm}$ range in the size by using carbonization in the presence of citric acid in the medium. The thermal decrease phenomenon of carbon dots was evaluated by a thermo gravimetric analyzer, leading to a five-fold increase in QY compared to nonreduced CDs. In an another immense effort, Dolai et al. prepared nanoparticles in the $\sim 2.4$ $\pm 0.5 \mathrm{~nm}$ range by using 6-O-(O-dilauroyl-tartaryl)-D-glucose as the source of carbon in the synthesis medium [95]. Several studies carried out for the synthesis of C-dots by carbonization technique are given below in Table 6 .

Table 6. Carbonization-based methods for synthesis of C-dots.

\begin{tabular}{cccc}
\hline Source material of carbon & Size of C-dots & Applications & References \\
\hline L-cysteine+ citric acid & $\begin{array}{c}\text { Near-spherical particles with } \\
\text { diameters in the range of 2-4 nm, } \\
\text { crystalline }\end{array}$ & $\begin{array}{c}\text { Fluorescent agent for cell } \\
\text { imaging }\end{array}$ & [96] \\
\hline Citric acid & $4.8-9 \mathrm{~nm}$ & [97] \\
\hline $\begin{array}{c}\text { 6-O-(O-O-dilauroyl-tartaryl)- } \\
\text { D-glucose }\end{array}$ & $\sim 2.4 \pm 0.5 \mathrm{~nm}$ & [95] \\
\hline
\end{tabular}


Some researchers still favor the pyrolysis approach for synthesizing CDs from precursor molecules. Pyrolysis is also a type of thermal deposition method, but it is almost irreversible in nature, in which various samples or organic materials have been subjected for the decomposition under the inert conditions. Under this inert atmosphere the physical and chemical changes occur in organic sample materials which lead to carbon-containing solid residues. Thus, pyrolysis usually uses controlled pressure and very high temperatures during the process [98].

In a faithful attempt under the $250{ }^{\circ} \mathrm{C}$ pyrolysis process, Bourlinos et al., fabricated a Gd (III)-doped carbon dot with the size range of $\sim 3.2 \mathrm{~nm}$ with the remarkable properties of dual fluorescence [99]. They used a combination of a Tris base, gadopentetic acid and betaine hydrochloride to harvest Gd (III)-CDs. Zheng et al., used a stepped forward pyrolysis method to synthesize a special category of carbon dots. L-aspartic acid and D-glucose were used as the reference molecules in this study. They reported $2.28 \pm 0.42 \mathrm{~nm}$ size of prepared material by using an aqueous $\mathrm{NaOH}$ medium containing the glucose and aspartic acid under the $200{ }^{\circ} \mathrm{C}$ temperature for $20 \mathrm{~min}$. In another work, Feng et al., used a thermal pyrolysis method to prepare carbon dots of citric acid. They used diethyl-ene-triamine during this process and prepared 5-8 nm sized carbon dots by transmission electron microscope (TEM) evaluation [100,101]. Several studies carried out for the synthesis of C-dots by pyrolysis technique are given below in Table 7.

Table 7. Pyrolysis-based method for synthesis of C-dots

\begin{tabular}{ccc}
\hline Source material of carbon & Size of C-dots & References \\
\hline L-aspartic acid and D-glucose & $\begin{array}{c}\text { Diameter of CDs was } \\
2.28 \pm 0.42 \mathrm{~nm}\end{array}$ & {$[102]$} \\
\hline $\begin{array}{c}\text { Citric acid via thermal pyrolysis method, } \\
\text { Capping agent: diethylenetriamine }\end{array}$ & $\begin{array}{c}\text { CDs was ranging from } \\
5 \text { to } 8 \mathrm{~nm}\end{array}$ & {$[101]$} \\
\hline $\begin{array}{c}\text { Tris base, gadopentetic acid, and betaine } \\
\text { hydrochloride }\end{array}$ & $\sim 3.2 \mathrm{~nm}$ & {$[99]$} \\
\hline
\end{tabular}

\subsection{Solvothermal Method}

The literature repealed with several studies related to the use of small organic molecules as the source of carbon to synthesize the carbon dots. Zhang et al., for instance, used carbon tetra chloride as a carbon source to make $\mathrm{N}$-doped Carbon dots with $\mathrm{NaNH}_{2}$ as a source of nitrogen via solvothermal method [103]. As a result, a remarkable carbon dot was prepared with the size of $3.3 \mathrm{~nm}$ along with the $0.5-5 \mathrm{~nm}$ height. The authors prepared a very crystalline product by using the solvothermal method that showed a graphite-like structure. In another work in solvothermal synthesis, Qian et al., used $\mathrm{SiCl}_{4}$ and hydroquinone to produce Si-doped CDs. In a typical stainless-steel autoclave, the authors used acetone as solvent made a mixture of $\mathrm{SiCl}_{4}$ and hydroquinone mixture in it and provided the heat at $200{ }^{\circ} \mathrm{C}$ for $120 \mathrm{~min}$. As a result, they prepared a Si-doped carbon dots product with a size of $7 \pm 2 \mathrm{~nm}$ [104]. Shan et al., used a solvothermal single-pot preparation process to develop boron doped carbon dots. They included carbon precursor hydroquinone, and boron source $\mathrm{BBr}$. As a result, they produced a B-doped carbon dots product with the size around $\sim 16 \mathrm{~nm}$. Several studies carried out for the synthesis of C-dots by hydrothermal and solvothermal technique are given below in Table 8.

Table 8. Synthesis of C-dots by the solvothermal method.

\begin{tabular}{|c|c|c|c|c|}
\hline $\begin{array}{c}\text { Source material of } \\
\text { carbon }\end{array}$ & Hydrothermal conditions & Size of C-dots & Applications & References \\
\hline Wheat bran & $180^{\circ} \mathrm{C}, 3 \mathrm{~h}$ & & Drug delivery & [105] \\
\hline Tartaric acid and bran & $\begin{array}{c}\text { Autoclave at } 150{ }^{\circ} \mathrm{C} \text { for } 8 \mathrm{~h} \text { in } \\
\text { the oven }\end{array}$ & $\sim 4.85 \mathrm{~nm}$ & $\begin{array}{l}\text { G-CQDs were used as a } \\
\text { fluorescent probe for detection } \\
\qquad \mathrm{Cu}^{2+} \text { ions }\end{array}$ & [106] \\
\hline
\end{tabular}




\begin{tabular}{|c|c|c|c|c|}
\hline Orange peels & $180^{\circ} \mathrm{C}, 12 \mathrm{~h}$ & & LEDs, photocatalysis & {$[107]$} \\
\hline $\begin{array}{c}\text { Cereals and grains } \\
\text { waste }\end{array}$ & $200^{\circ} \mathrm{C}, 12 \mathrm{~h}$ & & Imaging, sensing, labeling & \\
\hline Bamboo waste & $200^{\circ} \mathrm{C}, 6 \mathrm{~h}$ & & Bioimaging (in vivo) & [108] \\
\hline Lemon peels & $200{ }^{\circ} \mathrm{C}, 12 \mathrm{~h}$ & & Sensing and photocatalytic & [109] \\
\hline Coconut husks & $200^{\circ} \mathrm{C}, 3 \mathrm{~h}$ & & $\mathrm{pH}$ sensing & [110] \\
\hline Sugarcane bagasse & $190^{\circ} \mathrm{C}, 24 \mathrm{~h}$ & & Drug delivery & [14] \\
\hline Prawn shells & $180^{\circ} \mathrm{C}, 12 \mathrm{~h}$ & & Nitrite detection & {$[14,111]$} \\
\hline Wheat straw & $250^{\circ} \mathrm{C}, 10 \mathrm{~h}$ & & - & [112] \\
\hline Carbon tetra chloride & & $\sim 3.3 \mathrm{~nm}$ & - & [103] \\
\hline $\mathrm{SiCl}_{4}$ and hydroquinone & SS autoclave at $200{ }^{\circ} \mathrm{C}$ for $2 \mathrm{hr}$ & $7 \pm 2 \mathrm{~nm}$ & - & {$[104]$} \\
\hline $\begin{array}{c}\text { Hydroquinone, and } \\
\text { boron source } \mathrm{BBr}_{3}\end{array}$ & & $\sim 16 \mathrm{~nm}$ & - & [113] \\
\hline $\begin{array}{c}\text { Low-cost wastes of } \\
\text { willow bark }\end{array}$ & Hydrothermal + carbonization & & Glucose detection & {$[114]$} \\
\hline
\end{tabular}

\subsection{Ultrasonic Treatment}

Ultrasonic has been also identified as an efficient technique to develop various carbon dots; thus, so much literature has been associated with the synthesis of carbon dots by this method. In this technique, carbon precursors along with acid, alkali and other oxidants are kept under high ultrasound waves due to which there is a breakage of carbon particles into very small nanoparticles. There is continuous cavitation of the molecules. The use of high energy of ultrasonic waves avoids the complex post-treatment process, thereby realizing the facile synthesis of CQDs with a small size [115-117]. In a very comprehensive work, Li et al., prepared a fluorescent carbon dot along with the ability of water solubility. They used activated carbon employing the ultrasonic treatment approach helped through one-step $\mathrm{H}_{2} \mathrm{O}_{2}$ in the same year. The TEM findings showed that the surface of prepared carbon dots was rich in hydroxyl groups along with a detected size range of 5-10 nm [117]. Kumar et al., reported the synthesis of carbon quantum dots (CQDs) by using the sonochemical method and also described the detailed applications of CQDs in electronics. Pan et al., reported the synthesis of fluorescent CQDs by using the sonochemical method and applied them for sensing of food analysis [115,118]. Ultrasonication based CQD synthesis was first reported in 2011, by Li and his fellow members by using glucose in an acidic and basic environment. Li and his colleagues synthesized PL CQDs, of sizes below $5 \mathrm{~nm}$ [117]. Huang and Lu et al., reported the synthesis of fluorescent CQDs by the ultrasonication method functionalized with thiol-terminated polyethylene glycol. Here, due to the addition of a hydrophobic PEG group, the dispersibility of the CQDs increased in the aqueous phase. Moreover, it has also increased the biocompatible nature of the synthesized CQDS [119]. Lu et al., synthesized a blue, fluorescent N-CQD (size: 2.5-5.5 nm, QY: 3.6\%, average life: $3.02 \mathrm{~ns}$ ) by ultrasonic treatment of dopamine in dimethylformamide (DMF), which exhibited good stability of colloid and light in aqueous solution $[119,120]$. Several studies carried out for the synthesis of C-dots by the sonochemical technique are given below in Table 9.

Table 9. Synthesis of C-dots by the ultrasonic method.

\begin{tabular}{cccc}
\hline $\begin{array}{c}\text { Source material of } \\
\text { carbon }\end{array}$ & Size of C-dots & Applications & References \\
\hline Activated carbon & $5-10 \mathrm{~nm}$ & - & {$[117]$} \\
\hline Activated carbon & $5-10 \mathrm{~nm}$ & - & {$[121]$} \\
\hline
\end{tabular}

\section{Properties of CQDs}

The emerging new class of carbon nanomaterials has unique and remarkable properties, due to which it has drawn the attention of the whole scientific community. The 
CODs have unique physical, chemical and optical properties. The chemical property of CQD is highly important among all the properties due to their photoluminescence phenomenon, chirality and UV-absorption [122]. Typically, CDs can act as both electron acceptors and donors [123]. All these properties are discussed below in detail by citing relevant literature.

\subsection{Structural Properties of C-Dots}

Carbon dots (C-dots) are a novel group of nanomaterials that contain carbon and whose size is generally below $10 \mathrm{~nm}$ is size. Sun et al., claimed that quasi-spherical nanoparticles are carbon dots [124]. They have a diameter of less than $10 \mathrm{~nm}$ and some carbon dots are also hallow structured. Many researchers have already shown amorphous C-dots with geometry such as $\mathrm{sp}^{2}$ and some have been identified as $\mathrm{sp}^{3}$, in a diamond-like structure. The C-dots are circular or elliptical in shape, and others also have a quadrate, triangular and hexagonal structure, verified by high-resolution transmission electron microscope (TEM), tools for diffraction by scanning electron microscope (SEM) and X-ray diffraction (XRD) [124].

\subsection{Absorbance of C-Dots}

Due to the transition pie-pie* $\left(\pi-\pi^{*}\right)$ of double bonds $(C=C), C$-dots absorb in the short-wavelength region. Within the UV region (260-320 nm), they usually display heavy optical absorption, with a tail reaching up to the visible range [125]. C-dots are usually more effective at processing long wavelengths. Based on the surface passivation and the functional groups attached to its surface, their absorption properties vary from one C-dot to another [126].

\section{Mechanisms Involved in the Photoluminescence Phenomenon}

The mechanism of the photoluminescence of carbon dots is still widely debated, with the work focusing on finding the origin of photoluminescence dependency on excitation [127]. The search is exceptionally challenging due to the large diversity of synthesis methods and precursors which influence both the assembly and configuration of the CDs. The description suggested can be summed up in three key mechanisms:

The effect of the quantum captivity or the phenomenon associated with core emission caused by the conjugated carbon core $\pi$-domains; surface states due to the presence of carbon backbone-linked functional assemblies and molecular state in which the emission derives through free fluorescent or bound molecules.

\subsection{The Core Emission}

There is a direct link between the emission phenomenon that is generated because of excitation and the nanometer level dimension of the particles until the exploration of carbon dots, seeking a special effect that is called the quantum confinement effect (QCE) on the optical functionalities as for the various quantum dots [128]. Several publications investigating appearing indications for $\mathrm{QCE}$, due primarily to crystalline carbon core (CQD) observations.

In top-down synthesized CDs, Kang et al., recorded the significant red-shift of emission from the ultra-violet zone to near infra-red by increasing the dimension of carbon dots from 1.2 to $3.8 \mathrm{~nm}$ and associated the effect with the nanoparticles' graphite-like structures at a quantum-size [129]. Lately, the solvothermal framework enables the growth of crystalline carbon dots with related characteristics, requiring QCE, miraculously associated with surface oxidation [129].

The states among the carbon-cores engage in the PL of carbon dots by recombining radiative excitons in the center arising from the pie-pie* $\left(\pi-\pi^{*}\right)$ transition in the $\mathrm{sp}^{2}$ constellations supported by the phenomenon related to quantum confinement [128]. The core emission is mainly comparative at tinier wavelengths and has a little PL QY; however, the existence of graphic nitrogen enables changes in the absorption such as red-shifting of absorption as well as variations in the emission-related properties, even after once again 
referring to the core constructions role and besides the oxidation phase, it has been expected to enhance the $\mathrm{sp}^{3}$ shell-region and decrease the $\mathrm{sp}^{2}$ core structures, that are further perturbed by $\mathrm{N}$-doping, inducing emissive core trap states to form [47].

\subsection{The Surface States}

The surface states phenomena are the relatively most standard explanation for the peculiar carbon dots emission, associated with $\mathrm{pH}$-related variations, solvatochromic consequences, effects related to oxidation and topological functionalization [130]. The intrinsic and extrinsic surface centers can be differentiated by altering the narrative of semiconductor fields. Intrinsic surface conditions are because of the dissolution of the underlying lattice of the particle, while extrinsic centers are surface lattice deficiencies as a result of adsorbed or bonded compounds. Most of these are usually accountable for the outcomes related to the emission surface states, at which the carbon backbone hybridization and the connected chemical groups greatly affect the various levels of electronic dynamisms. The excitation-dependence of the emission has been associated with the oxidation processes involved on the surface by correlating the red-shift emission with an intensification in the oxidation of the surface [131]. Through means of quantum chemical measurements, the alteration of the electronic atmosphere through oxidation on $\mathrm{sp}^{2}$ carbons was demonstrated as the cause of the electronic emission rates in design graphene oxide [132].

Sun et al. observed that when using organic molecules surface passivation creates constant superficial energy set-ups that contribute to the PL emission [132]. The effect of multiple atoms on the surface, particularly different nitrogen molecules, adjusted the release features of carbon dots attributing the blue color discharge to pyrrolic $\mathrm{N}_{2}$, the green color to pyridinic $\mathrm{N}_{2}$ and the red PL to p-phenylenediamine alteration. Thus, the various colored discharges such as blue, green and yellow were associated with surface conditions due to $\mathrm{pH}$ variations and solvent properties in hydroquinone and EDA-prepared CDs. An XPS study found emissions were linked to surface-based imine groups and produced energy levels associated with defects [128].

\subsection{The Molecular State}

The basis of the model associated with the molecular state is the existence of the molecular materials that are fluorescent in nature, free or associated with the carbon dots' structure. Various organic molecules have been categorized such as (imidazo[1,2- $\alpha]$ pyridine-7-carboxylic acid (IPCA), 1,2,3,5-tetrahydro-5-oxo-7-indolizinecarbaldehyde, and 4hydroxy-1H-pyrrolo[3,4-c]pyridine-1,3,6(2H,5H)-trione (HPPT) have been accepted as accountable for blue (IPCA) and green (HPPT) emissions in bottom-up synthesis related with citric acid synthesis [74].

Excitation (the Kasha-Vavilov rule); therefore, supplementary appliances and/or the existence of a collection of discharging molecules are needed. The full spectral attributes of CDs can be effectively clarified by polycyclic aromatic hydrocarbons (PAHs). Thus, carbon dots can be called nanocrystals at molecular levels, where these poly aromatic hydrocarbons have been trapped in a $\mathrm{sp}^{3}$-hybridized carbon background. Because of their numerous band gaps, a collection of stacked PAHs, including perylene, anthracene and pyrene may provide for the reliance on release excitation phenomenon [133].

Since then, Righetto et al., reported permitted molecules using a coupling fluorescence correlation spectroscopy technique and paramagnetic resonance of time-resolved electrons [134]. However, on the other hand, the molecules that are bound to or incorporated within the layers, the recorded oscillations and turnings of carbon layers can provide for the expected hydrodynamic radius at molecular levels. Moreover, fluorophore materials have also been suggested to perform a part in the absorption and emission characteristics. CDs can be interpreted as synthetic objects, made from fluorophores, ultimately aggregated, within or connected to a carbonized heart, including these results [128]. That will further confirm the image, and it has been shown whether temperature and synthesis time can alter the molecular state/core balance. Several alternative approaches have been 
suggested to elucidate the development of carbon dots while process involved with hydrothermal phenomenon of CA and EDA involving specific carbonization and controlled carbonization of involved molecules, thereby promoting the creation of a mixture of diverse emission sites in the similar carbon dots or the creation of a dissimilar variety of diverse carbon dots characterized by their separate emissions [135]. Crosslink-enhanced PL system for polymer dots (PDs) were designed by dehydration, condensation, carbonization or assembly regions by non-conjugated polymers [136]. As such, PDs display an excitation-dependent emission characteristic attributed to the contribution of the centers that are fluorescent in nature as well as chemically amine-based rotating and vibrating gestures, which are inhibited by the polymeric cross-linked frames. From the perspective of solid-state applications, surface states can also be implicated in engineering the secretion from carbon dots while assisted in hosting environments, such as silica media or zinc oxides.

\subsection{Factors Affecting the Properties of $\mathrm{C}$-dots}

There are several factors which govern the properties of carbon dots, for instance reaction temperature and time, $\mathrm{pH}$ of the synthesis conditions, type of precursor material used and amount of carbon present in them. The properties of C-dots also depend on the heteroatom co-doping of the C-dots and surface passivation. The source of carbon dots, generally affects the fluorescence property of the C-dots, as in one study carbon dots prepared from pineapple peels were completely degraded within a few days due to fungal activity, while C-dots prepared from cucumber and peels showed better stability and no fungal degradation was observed. Synthesis of CDs involves carbonization, which is an endothermic process, so temperature plays a key role in the synthesis of carbon dots. An experiment conducted on various types of plant leaves, by pyrolysis methods to obtain carbon dots. It was found that, though similar pyrolysis conditions were applied for all the leaves, the properties were different for CDs. The temperature in pyrolysis should neither be too high or too low, as a lower temperature will result in incomplete carbonization while a high temperature will over oxidize the samples, ultimately resulting in deteriorated C-dots. Their surface structure will be destroyed at high temperature. The reaction time of C-dots' synthesis has almost a similar effect as that of temperature, as higher reaction time will destroy the surface structure while lower temperature will lead to inappropriate morphology. The optical properties of CDs are temperature dependent i.e., the reaction time have direct effect on the optical properties of CDs. Due to the non-availability of appropriate reaction temperature, the end-product will end up with a useless one [137]. The CDs obtained from different carbon sources and different methods, the influence of the $\mathrm{pH}$ value of the solution on their fluorescence emission intensities varies. The $\mathrm{CDs}$ have wide range of $\mathrm{pH}$ workability. Some of the $\mathrm{CDs}$ work better at neutral $\mathrm{pH}$ while some work better at an acidic $\mathrm{pH}$; some have optimal features at alkaline $\mathrm{pH}$. Such types of $\mathrm{CDs}$ are suitable for $\mathrm{pH}$ sensor manufacturing as they can withstand variations in $\mathrm{pH}$. The CDs made from coconut husks have a wide range of functional groups on their surface which makes them suitable for making $\mathrm{CDs}$ for $\mathrm{pH}$ sensing. When there was an increase in $\mathrm{pH}$ from 4 to 12, there was protonation and deprotonation of carboxyl groups present. Consequently, there was a change in the electrostatic charging property and hence the fluorescence emission property of CDs decreased gradually.

There are several studies where heteroatom-doping have been used in order to enhance the features of CDs. By introducing heteroatom in the framework of CDs one can easily govern the electrical properties as well as chemical features associated with internal and surficial C-dots. C-dots are generally doped with $\mathrm{N}$ and $\mathrm{S}$ atoms, where the former is more electronegative than $\mathrm{C}$, and the later one regulates the energy state density of CDs. Due to $S$ doping, there is an enhanced fluorescence emission intensity of C-dots [138].

The CDs are generally functionalized with various functional groups in order to enhance their fluorescence emission intensity, which as a result increases their applicability in the bio-analytical field. Due to surface functionalization, the surface defects will be de- 
creased while exciton-hole recombination probability will be increased. Due to this surface passivation of CDs, there will be minimized or no agglomeration of CDs and enhanced fluorescence emission intensity [139].

\section{Emerging Applications of Carbon Dots}

Although using excellent properties such as low toxicity [140] and good biocompatibility makes CQDs ideal materials for bioimaging, biosensors and drug delivery applications, CQDs can, however, offer advantages in catalysis, sensors and optronics based on their excellent optical and electronic properties [123].

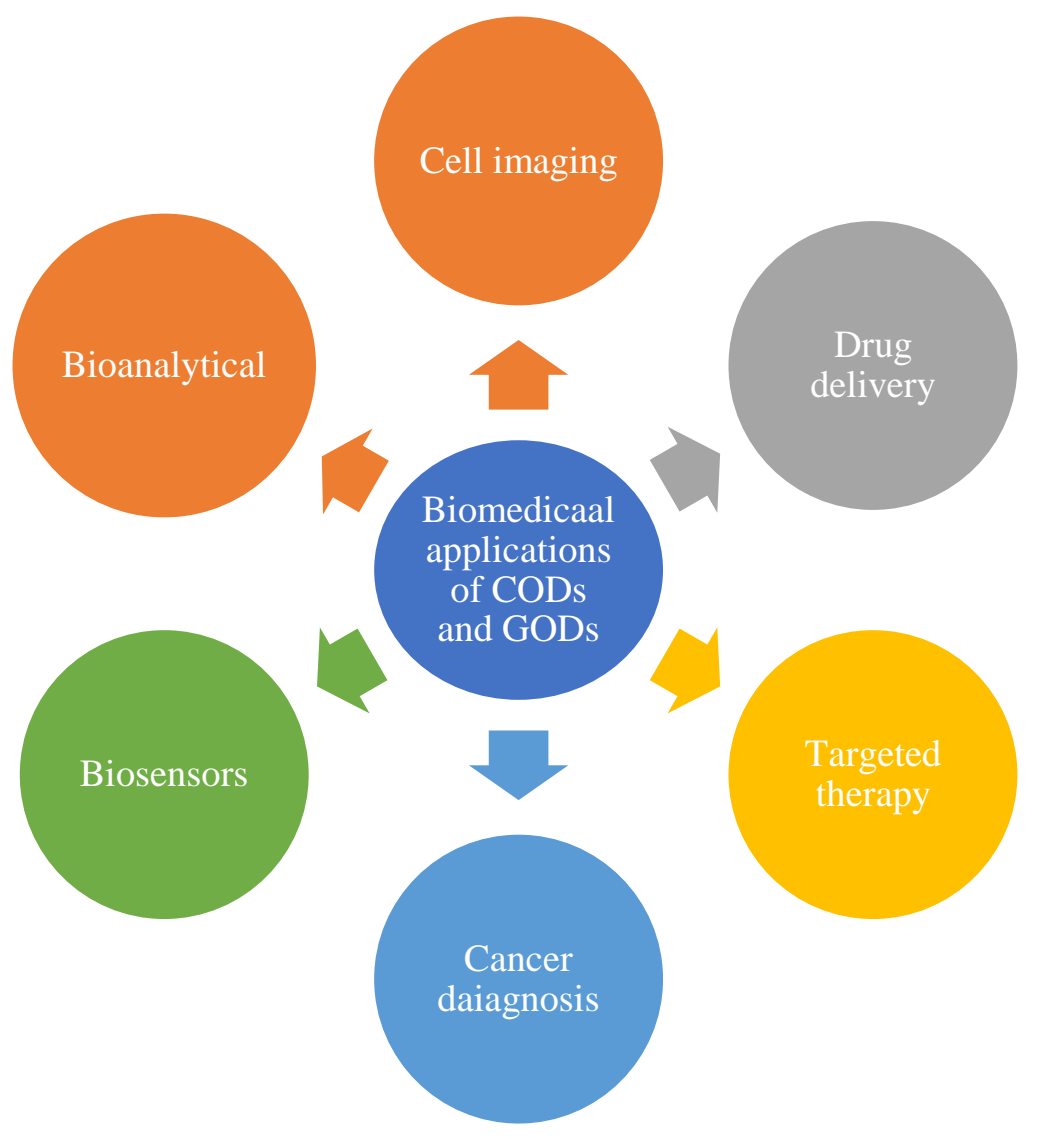

Figure 3. Biomedical applications of CODs and GODs. 


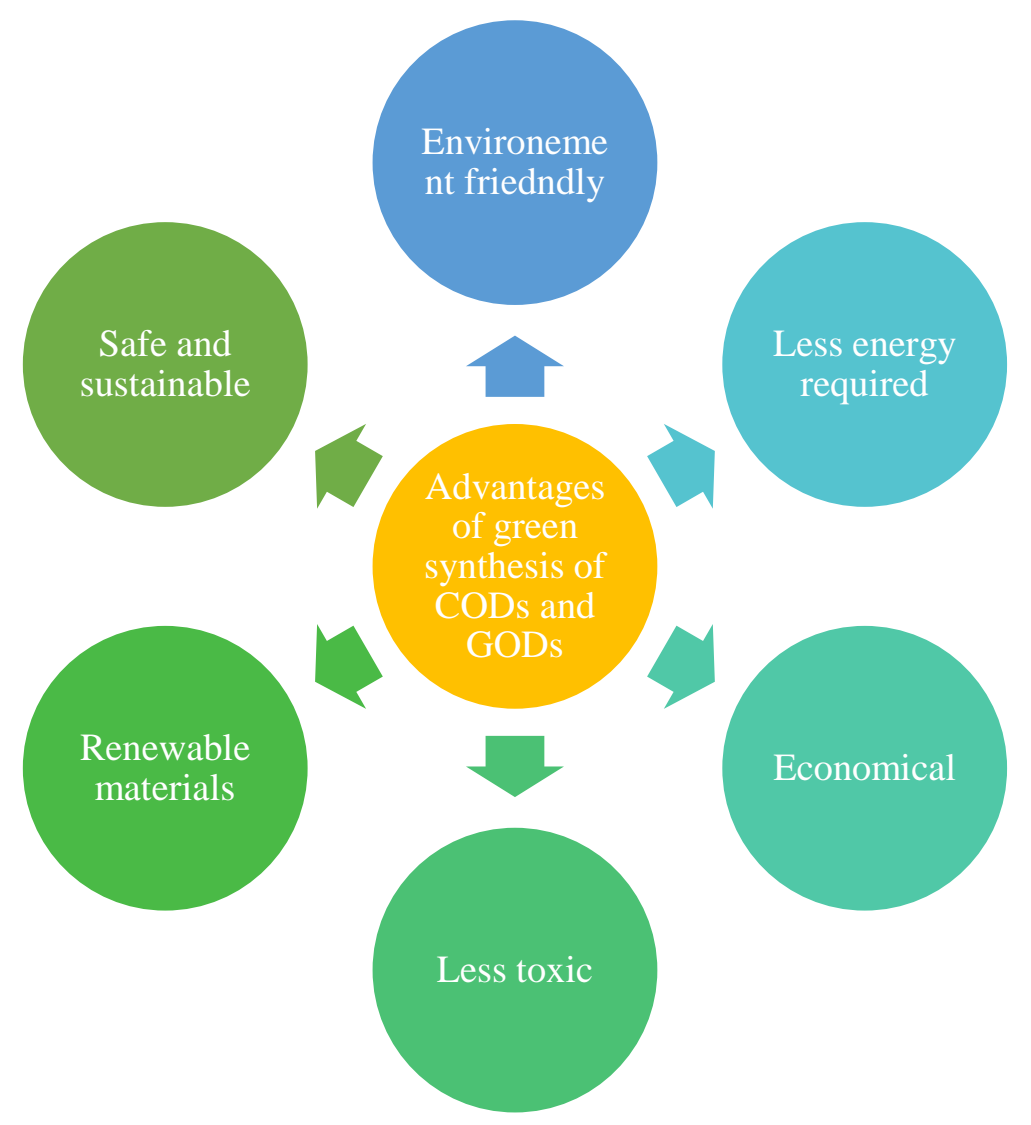

Figure 4. Advantages of green synthesis of CODs and GODs.

\subsection{Bioimaging}

Bioimaging is a technique for imaging and direct observation of biological methods in real-time which is often used to obtain the information from the 3D morphology of the observed specimen from the outside, i.e., without physical interference [123]. Because of its fluorescence emissions and biocompatibility, CQDs are being used for bioimaging. In vivo images can be generated by injecting solvents carrying CQDs into a living organism for identification or treatment purposes. Organic dye-conjugated-CQDs are used as an efficient fluorescent $\mathrm{H}_{2} \mathrm{~S}$ probe. $\mathrm{H}_{2} \mathrm{~S}$ presence may change blue to the green emission of organic dye-conjugated-CQDs. Therefore, organic dye-conjugated-CQDs are able to imagine changes in the physiologically important rates of $\mathrm{H}_{2} \mathrm{~S}$ using a fluorescence microscope. Some of the CDs have been used for the diagnosis of cancer and phototherapies. For instance, $200 \mu \mathrm{l}$ of CQDs and wheat straw were given to the mice from the tail vein, and later on the fluorescence property was investigated. Zhang and Hong revealed the synthesis and mechanism of photoluminescence and their applications in our everyday life. Das et al., reported the use of carbon dots in the field of medicine and bio imaging [123]. Shabasy et al., also reported the detailed applications of C-dots in the biological field including bio imaging [140]. Several studies were carried out where CDs have been used for bioimaging; these are briefed in Table 10. 
Table 10. Applications of C-dots in bioimaging.

\begin{tabular}{cccc}
\hline Source material of carbon & Methods of synthesis & Applications & References \\
\hline Onion waste & Hydrothermal & $\begin{array}{c}\text { Multicolor imaging and Fe3+ } \\
\text { detection }\end{array}$ & {$[141]$} \\
Lychee waste & Solvohydrothermal & $\begin{array}{c}\text { multicolor cell imaging and Fe3+ } \\
\text { detection }\end{array}$ & {$[141]$} \\
\hline Cow dung waste & Chemical oxidation & $\begin{array}{c}\text { live-cell imaging with } \\
\text { subcellular selectivity }\end{array}$ & {$[142]$} \\
\hline Banana peel waste & Hydrothermal & In vivo bioimaging & {$[143]$} \\
\hline Walnut shells & Carbonization & Intracellular bioimaging & {$[144]$} \\
\hline Wheat straw and cereals & Hydrothermal & $\begin{array}{c}\text { Cell imaging and in vivo } \\
\text { bioimaging }\end{array}$ & {$[112]$} \\
\hline
\end{tabular}

\subsection{Sensing}

CQDs have also been used as biosensors for their versatility in alteration, high water solubility, nontoxicity, good photostability and excellent biocompatibility. Biosensors based on materials based on CQD and CQs may be used to track cellular copper, glucose, $\mathrm{pH}, \mathrm{H}_{2} \mathrm{O}_{2}$ trace levels and nucleic acid visually. A useful application is lateral flow assays with nucleic acid. The detecting tags on the amplicons are identified by their associated antibodies and fluorescence patterns from the corresponding CQDs. The fluorescence of CQDs reacts effectively to $\mathrm{pH}$, local polarity and the existence of metal ions in solution, which further extends their capacity for nano sensing applications, for example in pollutant analysis. Shabasy et al. and Das et al. reported the applications of carbon dots especially quantum dots and graphene dots in the field of sensing. It has been used widely for sensing of temperature, $\mathrm{pH}$, light, phase, solvent, pressure and multi-sensitivity $[123,140]$. Several studies were carried out where CDs were used for sensing $\mathrm{pH}$ and organic and inorganic pollutants from water bodies; these are briefed in Table 11.

Table 11. Applications of C-dots in the sensing field.

\begin{tabular}{|c|c|c|c|}
\hline Source material of carbon & Morphology of C-dots & Applications & References \\
\hline Bagasse waste & \multirow{5}{*}{ Hydrothermal (HT) } & $\mathrm{Hg}^{2+}$ detection & [145] \\
\hline Lignocellulos waste & & Copper ion & [146] \\
\hline Crown daisy leaf waste & & Copper ion & [147] \\
\hline Sargassum fluitans & & DNA detection & [148] \\
\hline Mango peels waste & & Mesotrione detection & [124] \\
\hline Glucose source & & Sensing & {$[123,140]$} \\
\hline Palm shell waste & Ultrasonic & nitrophenol detection & [149] \\
\hline Waste tea residue & \multirow{3}{*}{ Chemical oxidation } & tetracycline detection & [14] \\
\hline Waste candle soot & & $\mathrm{Hg}^{2+}$ and $\mathrm{Fe}^{3+}$ detection & [150] \\
\hline Kerosene fuel soot & & picric acid, $\mathrm{Fe}^{3+}$ and $\mathrm{Cu}^{2+}$ detection & [151] \\
\hline
\end{tabular}

\subsection{Drug Delivery}

CQDs' non-toxicity and biocompatibility enables them to use wide-ranging applications in biomedicine including drug carriers, fluorescent tracers and monitoring drug release. This is evidenced through the use of CQDs as photosensitizers in photodynamic therapy for cancer cell destruction. There are numerous examples in the literature where C-dots have been used for the delivery of numerous drugs inside humans and animals. The major advantage of such C-dot-based drug delivery is that the carriers are non-toxic, $\mathrm{PL}$, and biocompatible in nature. Due to their small size and enhanced surface area, there is faster uptake of C-dots as a carrier by the cells. Consequently, there is a minimum adverse effect on the carrier molecule. It has been sued successfully for the release of the 
doxorubcin drug. Doxorubicin conjugated with GODs exhibited a potent cytotoxic activity against U251 glioma cell GQDs through hydrogen bonds. C-dots have also been used for the delivery of SN38 by using PEGylated nanographene. By using graphene quantum dots, pancreatic cancer cells were investigated, along with biodegradable polyester vectors [140]. Several studies were carried out where CDs have been used for drug delivery; these are briefed in Table 12.

Table 12. Applications of C-dots in drug delivery.

\begin{tabular}{|c|c|c|c|}
\hline Source material of carbon & Methods & Applications & References \\
\hline Wheat bran & HT & DD & [105] \\
\hline Sugarcane bagasse & Burning and HT & $\mathrm{DD}$ & [152] \\
\hline Waste sago bark & Catalyst-free pyrolysis & Anticancer drug delivery & [153] \\
\hline Bamboo leaves & Reflux & DD, tumor imaging & {$[154]$} \\
\hline Crab shells & Microwave & $\mathrm{DD}$ & [155] \\
\hline
\end{tabular}

\subsection{Catalysis}

Carbon dots (CDs), with sizes below $10 \mathrm{~nm}$ found efficient catalyst or photocatalysts [154]. The versatility of surface modification towards different CQD groups enables them to absorb lights of various wavelengths that provides good prospects for photocatalytic applications. The P25 $\mathrm{TiO}_{2}$ composites modified by CQDs exhibited enhanced photocatalytic $\mathrm{H}_{2}$ evolution under $\mathrm{UV}-\mathrm{V}$ is irradiation. The CQDs act as a repository for electrons to increase separation efficiency of the P25 electron-hole pairs [156].

\subsection{Optronics}

CQDs have the ability to act as materials for dye-sensitized solar cells, organic solar cells, supercapacitors and tools for light pollution [157]. CQDs can be used as photosensitizers in dye-sensitized solar cells and the performance of photoelectric conversion is greatly enhanced. Hybrid silica-based sol embedded in CQD can be used as clear fluorescent paint [158]. The optical properties of the CQDs can be enhanced and improved by synthesizing multicolor emitting CDs. It has been proven in the literature, theoretically, that the electronic features of carbon-based nanoparticles could be monitored by shape, by morphology, chemical composition and doping. In particular, CDs were considered as nanoparticles with $\mathrm{sp}^{3}$-hybridized amorphous carbon cores that contain partially sp-hybridized carbon domains, and it was predicted that the emission of CDs can be redshifted by increase of hybridization factor of those domains within CDs [159]. Another theoretical investigation showed that covalent-bonded dimers of polyaromatic hydrocarbons at the CDs surface, in contrast to non-interacting monomers, resulted in a redshift and broadening of the PL band, with a decrease in its intensity [160]. CQDs are widely used in dyesensitized solar cells, LEDS, photovoltaic cells, electroluminescent CD-based LEDs and CDs in Perovskite Solar Cells. Several studies were carried out where CDs were used for catalysis, photocatalysis optronics and in forensics; these are briefed in Table 13.

Table 13. Applications of C-dots in catalysis, optronics and forensics.

\begin{tabular}{cccc}
\hline Source material of carbon & Methods & Applications & References \\
\hline Waste frying oil & HT & Photocatalyst & {$[14]$} \\
\hline $\begin{array}{c}\text { Citrus fruits peel waste } \\
\text { (lemon+orange) }\end{array}$ & HT & Phtocatalyst and sensing & {$[161]$} \\
\hline Lignocellulose waste & Pyrolysis & $\begin{array}{c}\text { Photocatalyst attached to } \\
\text { pollutant utilization }\end{array}$ & {$[162]$} \\
\hline Bitter apple waste & Pyrolysis & Photocatalyst & {$[163]$} \\
\hline Waste food & HT & Light emitting diodes & {$[164]$}
\end{tabular}


The small size and reactive nature of CQDs makes them highly suitable for visualization of latent fingerprints, due to which they can be easily bind with the ridge of fingerprints. One major advantage with the use of CQDs for latent finger printing is that there is no effect of aging of organic and inorganic content from the finger print samples. As, with aging, the organic and inorganic content of fingerprints fades away and becomes difficult to detect for the investigators. Earlier, it was reported by Wang and his co-workers, that latent fingerprints can be collected using carbon dots made from pig intestines. They also found out that carbon dots imbedded in polyvinyl alcohol (PVA) due to long term stability of films give a highly detailed image of the fingerprint. Recently, it has been seen that citric acid, which acts as a source of carbon with diethylenetriamine, gives good results. Carbon dots are mixed in liquid PVA and are cast on the fingerprints and the casted film is allowed to dry. After dried, fingerprints can be visualized with UV flashlight within a frequency around 395-400 nm. G-CDs method, SiO $@$ @ C-dot powder, N, S-SFCD method and Carbon polymer dots (CPDs)-starch powder successfully used for the detection of latent fingerprints $[165,166]$.

\subsection{Antibacterial Activity of CDs}

There are numerous examples from the literature where CDs have been used for to control the microbial activities. Among all the microorganisms, CDs have been widely used against viral diseases. Some of the investigators have revealed that CDs can interact with viruses and minimize the infection arising from them. Amino acid- or boronic acidconjugated CDs have been used against the human herpes virus type-1 and exhibited that the entry of viruses was stopped [167]. In another study, phenylboronic acid conjugated CDs have shown potential against highly infectious virus diseases, such as coronavirus. Mechanistically, it may be due to the human coronavirus-229E entrance inhibition, caused by the interaction of the boronic acid functions of CQDs with the HCoV229E S protein through pseudo-lectin-based interactions [168]. Besides this, CDs have also been used for several bacterial pathogens, such as Escherichia coli, Pseudomonas aeruginosa and Staphylococcus aureus, which causes diarrhea, pus and burn infections and food poisoning and skin infections, respectively. The labelling of CDs helps in the fluorescence activity by which dead bacterial cells can be easily detected. These labelled CDs initially interact with the Gram-negative bacteria and then after adsorption on their surface exhibit fluorescence emission at higher intensity. The mode of action of such CDs is due to the imbalance in the surface charge and insertion of CDs into the surface by long alkyl chains which ultimately leads to the destruction of bacterial cell wall and inhibition of bacteria. In one study, organosilane loaded with quaternary ammonium compounds and exhibited antibacterial activity against Gram-positive bacteria. Here, glycerol was used as a source of carbon, due to its easy availability and economical nature [140,169].

Besides this, there are several studies that have been done by numerous scientists to expand and modulate the fluorescence properties of CDs, heteroatomic doping and surface functionalization which were used to improve the physicochemical properties of CDs used in monitoring and antibacterial applications [170].

\subsection{Applications of CDs in Chemical Warfare}

Warfare agents (biological or chemical) has now become the first choice of every country against the wars due to their more impact and severity in comparison to physical mass of destruction. Bacillus anthracis (plague), Francisella tularensis (tularemia), Yersinia pestis (plague) and Brucella abortus (brucellosis) etc. have been used earlier as bioweapons either by armies or terrorists for the mass destruction of their opponents. Though government bodies have banned the use of such bioweapons, still some of the countries are using them secretly. Similarly, there are certain chemical compounds (phosgene, ricin, hydrogen cyanide etc.) that are used in place of bioweapons for the mass destruction of opponent countries or organizations. Most of these chemical warfare agents are colorless and could not be detected easily so there is a need for highly sensitive sensors for the detection of such 
agents. By using such highly sensitive chemical sensors, one could prevent the large destruction of an army or people at the earliest stage. There are several pieces of literature where CDs have been used as a warfare agent and also for the sensing the harmful chemicals used during wars; for instance, Chang et al. used CDs chelated Europium, for the ratiometric fluorescent detection of biomarkers for biological warfare agents [25]. Kumar et al. developed a CNT-based gas sensing agent $\left(\mathrm{NO}_{2}\right)$ for the study of simultaneous reversible and irreversible adsorption [27]. Tuccitto et al. synthesized a fluorescent nanosensor, based on carbon nanoparticles (CNPs) which was covalently functionalized with ethanolamine arms for interaction with nerve agents [171]. Again Tuccitto et al. synthesized a fluorescence CDs nanochemosensor, for the selective detection of amino acids [26]. Tuccitto et al., also developed functionalized CDs, for the supramolecular sensing of the chemical warfare agents' simulants [28]. Similarly, Paul et al., used gold nanoparticles for the detection and degradation of chemical warfare stimulants [24]. Butera et al., also summarized the importance of CDs in supramolecular sensing of chemical warfare agents [23].

\section{Surface Functionalization of CDs}

Pathogenic bacteria monitoring using CDs can be categorized into two types, direct and indirect monitoring. Direct labeling and detection of pathogenic bacteria using CDs needs different surface groups on the CDs, or different surface charges, thus encouraging different bacteria to be labeled and detected [172]. Otis et al. presented CDs, used as precursors of citric acid and aminoguanidine. It may selectively mark strains of Pseudomonas aeruginosa. Co-doped CDs (PNSCDs) with phosphorus, nitrogen and sulfur can selectively identify dead microbial cells but not live ones [173] [73]. Fluorescent CDs have been synthesized from bacteria and used to mark dead microbial cells instead of live ones [174].

Indirect monitoring of pathogenic bacteria generally requires the application of $\mathrm{CDs}$ with a selective binding group to detect pathogenic bacteria, coupled with a labeling probe [175]. To couple the labeling probe, the surface group (e.g., amino group, carboxyl group, or sulfhydryl group) of the CDs need to be modified. Specific elements of identification, including antibodies, peptides and aptamers, stain and detect pathogenic bacteria. An inventive fluorescent aptasensor for the detection of $P$. aeruginosa was developed by graphene oxide quantum dots (GOQDs) [176]. Yang et al., prepared breakable organosilicon nano capsules (BONs) packaged with $\mathrm{CDs}$ and used the CDsBONs to detect $S$. aureus in a fluorescent immunoassay.

Amides and amines of $\mathrm{N}$-doped-CQD have played a significant role in improving the antibacterial activity [177]. Electrostatic interactions between CQDs and bacterial surfaces were associated with their microbial killing mechanisms. A new approach for antimicrobial treatment is provided by amino terminal CDs $\left(\mathrm{CDs}-\mathrm{NH}_{2}\right)$ modified with ampicillin (AMP)[178]. The AMP-CDs and reactive oxygen species (ROS) produced under visible light irradiation are highly effective at preventing E. coli's growth. Amine-functionalized lauryl betaine-immobilized CDs provide antimicrobial properties, leading in the killing of Gram-positive (S. aureus).

\section{Hetero Atomic Doping}

The fluorescence features and the quantum yield (QY) of the CDs are vital for observing pathogenic bacteria. Heteroatomic doping is one of the most effective methods of fluorescence regulation and improvement CD properties. This approach will alter their underlying electronic characteristics and give new active sites [14]. These were used in heteroatomic doping of CDs boron, magnesium, nitrogen, sulfur, phosphor, terbium $\mathrm{Si}$, $\mathrm{F}$, Se and metal ion $\left(\mathrm{Mn}^{2+}, \mathrm{Fe}^{2+}, \mathrm{Co}^{2+}\right.$ and $\left.\mathrm{Ni}^{2+}\right)$. The synthesis of high visible fluorescence phosphorus, nitrogen co-doped CDs (PNCDs), discovered that they could still act as an efficient and accurate fluorescent sample to identify the living state of microbial cells. PNSCDs can identify dead bacteria, selectively, though not live bacteria (Song et al. [179]). Carbon nitride doped with Fluorine $\left(\mathrm{F}-\mathrm{C}_{3} \mathrm{~N}_{4}\right)$ quantum dots were synthesized with such a high QY of 39.03 per cent that was used, effectively, as a microbial imaging PL sensor 
[180]. Hojaghan et al., made extremely luminescent, graphene doped with nitrogen quantum dots (N-GQDs) and used them to identify S. aureus and E. coli as a fluorescent probe [181].

$\mathrm{N}$-doped-CD amides and amines played an immense role in enhancing their antibacterial activity. The ability of oxygen species to activate via the CD surface has a definite antibacterial effect [177]. CDs co-doped with nitrogen and zinc (N, Zn-CDs) have demonstrated significant bacteriostatic activity against $E$. coli was $1 \mathrm{mg} \mathrm{mL}^{-1}$ with minimum inhibitory concentration (MIC). Jian et al., prepared spermidine doped-CDs with super cationic nitrogen that demonstrated effective antimicrobial activity against both sensitive multidrug-resistant bacteria [182]. Inspection of the proposed pathways showed that the super cationic N-CDs with highly positive charge results in severe breaking of the cellmembrane bacteria. Liu et al., used metronidazole as antibiotic to produce CQDs through a simple hydrothermal process. They produced a form of CQDs capable of detecting binding anaerobes through photoluminescence and being successively effective against these bacterial [183]. Thakur et al., conjugated the antibiotic ciprofloxacin hydrochloride to the surface of CQDs made from gum Arabic in order to generate CiproCQDs using a microwave-assisted synthesis process [184]. So, CQDs can also serve as carriers of drugs. Their study results revealed that Cipro CQDs have shown increased antimicrobial activity against the Gram-positive and Gram-negative bacteria tested [184]. Scott et al., used polyamines as the original organic raw material and used simple methods of pyrolysis, super cationic carbon quantum dots (CQDs) could be rendered quickly. Since polyamines are natural products and the preparation method was green, these CQDs derived from polyamines show low toxicity and high biocompatibility; however, they possess high antibacterial activity. Shanka et al., synthesized CDs as a source of carbon from carbohydrate and cysteine (Cys) and o-phenylenediamine (OPD) as a source of nitrogen. CDs based on OPD have been more successful against $E$. coli with a rating of IC50 of $\sim 200 \mu \mathrm{g} / \mathrm{mL}$ compared to Cys-based CDs while fluorescence emissions for later CDs were high. The hydrophilic CQDs were encapsulated in polyurethane polymer by Maria et al., using simple swellencapsulation-shrink Cyst/PU nanocomposite had also been displayed to be bactericidal towards $S$. aureus and E. coli after $1 \mathrm{~h}$ of BL irradiation at 470nm. The use of biodegradable starch as precursor has been documented by Verma et al., using microwave-controlled synthesis of catalytic fluorescent carbon dots. The synthesized C-dots demonstrated catalytic activity in the Ag NPs' photo-reduction [185]. This treatment of Ag NPs and C-dots has been observed to be highly bactericidal, with substantially low silver concentration compared to Ag NPs. The composite was capable of penetrating the bacterial cell wall and resulted in higher ROS production levels. Hao et al., present a one-step electrochemical method of producing low-toxic and degradable carbon dots (CDs) using vitamin C. Such newly produced CDs possess high broad-spectrum antibacterial activity and antifungal activity even at low concentrations, although they break the bacterial walls during the diffuse entry, disrupt the secondary structures of bacteria and fungus DNA/RNAs and suppress essential gene expressions in order to ultimately kill the bacteria and fungus. Niu et al., have been provided with a one-step pyrolysis method to synthesize NCDs with excellent water solubility, good stability and 28\% high quantum yield [186]. Due to the close interaction between the nitrogen doped CDs and antibacterial drugs, the detection efficiency of NCDs for antibacterial drugs has been shown to effectively improve fluorescence [186]. Han et al., prepared cow milk-derived carbon dots (CMCDs) which have been produced via hydrothermal cow milk treatment, and the as-prepared CMCDs have been removed by ethyl acetate to produce amphiphilic CMCDs (ACMCDs) [187]. A solvent casting method was used to create the novel ACMCD-Ag/polymethylmethacrylate nanocomposite antibacterial film. The nanocomposite antibacterial film is considered to be of great importance in applications because of its outstanding antibacterial, light-admitting and versatile properties [187]. Jin et al., demonstrated a one-step method to synthesize AgNPs. The surface characteristics of AgNPs might affect the stability of AgNPs characterized by various bactericidal effects. Such small AgNPs demonstrate stronger consistency in the culture medium which leads to excellent bactericidal activity which can 
fully inhibit Escherichia coli (E. coli) growth at a concentration of $150 \mu \mathrm{M}$ of silver atoms [188].

The following are possible frameworks for AgNP antibacteria:

(i) AgNPs can be readily absorbed into E. coli's surface and damage outer membrane permeability and fluidity [189].

(ii) Smaller sized AgNPs $(7.3 \pm 1.0$ and $6.1 \pm 0.8 \mathrm{~nm})$ that permeate the E. coli membrane to associate with the respiratory chain and DNA.

(iii) $\mathrm{Ag}+$ release can trigger the death of E. coli.

\section{Future Perspectives}

The carbon dots are emerging nanomaterials in every field due to their unique and remarkable properties. Though they could be synthesized by various physical, chemical and biological methods, the emphasis has to be given to the biological route since it would be economical and eco-friendly. Besides this, the biologically synthesized carbon dots will be biocompatible, which will boost their application in the field of biomedicine, especially in drug delivery.

\section{Conclusions}

Carbon dots have gained huge attention in the last decade, due to which they are widely used in the field of material science, environmental cleanup and medicine. They are widely used in medicine due to their biocompatible nature and non-toxic effects. They could be made more effective and specific by surface functionalization by using any chemicals. The synthesis of carbon dots by the green route is a highly preferred approach. If, the source material for carbon dots is waste carbon materials, then the carbon dots will be economical as well as eco-friendly. The green route synthesis will also minimize the pollution in the form of solid waste from our environment. In future, they would be used for targeted drug delivery, as drug carriers and in the agricultural industries.

\section{Acronyms}

2-AP-2-aminopyridine

AA-Ascorbic acid

AcD-Arc discharge

AEAPMS-N-( $\beta$-aminoethyl)- $\gamma$-aminopropyl methyl dimethoxysilane

AFM-Atomic Force Microscopy

$\mathrm{Ag}-$ Silver element

AgNP-Silver Nanoparticles

AMP-Ampicillin

$\mathrm{Au}-$ Gold

$\mathrm{BBr}_{3}-$ Boron tribromide

$\mathrm{Ca}-$ Calcium

$\mathrm{Ca}-$ Citric acid monohydrate

$\mathrm{Cd}$-Cadmium

CD or C-dots-Carbon Dots

$\mathrm{CD}-\mathrm{CH}$-carbon dots-chitosan

$\mathrm{Cm}-$ Centimeters

CMCDs-Cow milk-derived carbon dots

CNPs-Carbon nanoparticles

CNTs-Carbon Nano Tubes

CQD-crystalline carbon core

$\mathrm{Cu}-$ Copper

$\mathrm{Cu}-$ Copper

Cys-Cysteine

DD-Drug Discovery

DEG-Diethylene glycol

DMF-Dimethylformamide 
DNA-Deoxyribonucleic acid

ECE-Electrochemical exfoliation

FCD-Fluorescent carbon dots

$\mathrm{Fe}_{3} \mathrm{O}_{4}$-Iron oxide

FG-Functional groups

$\mathrm{HAuCl}_{4}-$ Hydrogen tetrachloroaurate(III) hydrate

$\mathrm{Hg}$ - Mercury

HPPT-4-hydroxy-1H-pyrrolo[3,4-c]pyridine-1,3,6(2H,5H)-trione

HT-Hydrothermal

IPCA-Imidazo[1,2-a]pyridine-7-carboxylic acid

LA - Laser ablation

LED-Light emitting diode

MIC-Minimum inhibitory concentration

$\mathrm{MnO}_{2}-$ Manganese dioxide

MWCNTs-Multi Walled Carbon NanoTubes

$\mathrm{NaNH}_{2}$-Sodium amide

$\mathrm{NaOH}-$ Sodium Hydroxide

$\mathrm{Ni}-\mathrm{Nickel}$

$\mathrm{Nm}$-Nanometers

NPs-Nanoparticles

NR-CDs - Nitrogen rich blue, fluorescent carbon dots

OPD-O-phenylenediamine

PAHs-Polycyclic aromatic hydrocarbons

PD-Polymer dots

PEG-Polyethylene glycol

$\mathrm{pH}-$ Potential of hydrogen

PL-Photo luminescence

PNSCDs-Pseudomonas aeruginosa.

PPEIE-Poly (propionyl ethylene-imine-ethyleneimine)

PPEI-EI-Poly(propionylethyleneimine-co-ethyleneimine

$\mathrm{Pt}-$ Platinum

PVA-Polyvinyl alcohol

QCE-Quantum confinement effect

QD-Quantum Dots

QY-Quantum yield

$\mathrm{RB}$ - Rose Bengal (RB)

ROS-Reactive oxygen species

$\mathrm{Rpm}-$ Rotations per minute

SC-Sodium citrate

Se-Selenium

$\mathrm{Si}-$ Silicon

$\mathrm{SiCl}_{4}-$ Silicon tetrachloride

SWCNTs-Single-wall carbon nanotubes

Tarp-Tryptophan

TEM-Transmission Electron Microscopy

TETA-Triethylenetetramine

$\mathrm{TiO}_{2}$ - Titanium di oxide

TTDDA -4, 7, 10-trioxa-1,13-tridecanediamine

UA-Uric acid

UV-Vis-Ultraviolet visible light

XRD-X-ray diffraction

Zn-Zinc

Author Contributions: Conceptualization, A.K., V.K.Y.; methodology, V.K.Y.,A.K., V.D., and V.T..,; validation, K.K.Y,., S.I..., V.D., and A.A.; formal analysis, V.K.Y.,V.D., A.K., and C.T.S; resources, V.T., K.K.Y.,S.I., V.D., and A.A., and C.T.S.; writing-original draft preparation, A.K.,V.K.Y., V.D.; 
writing - review and editing, A.K., V.K.Y.,V.T.., A.A., and C.T.S; supervision, V.K.Y.., A.A., and S.I.; project administration V.K.Y., V.D., V.T., K.K.Y., S.I., and C.T.S; Funding acquisition, K.K.Y,., S.I.., V.T., and K.K.Y.; Software's, A.K., V.K.Y., V.D., A.A., and C.T.S,. All authors have read and agreed to the published version of the manuscript.

Funding: The funding for the current work was provided by Deanship of Scientific no Research, King Khalid University (KKU), Abha-Asir, Kingdom of Saudi Arabia for funding this research work under the grant number GRP/93/42.

Institutional Review Board Statement: Not applicable

Informed Consent Statement: Not applicable.

Data Availability Statement: Not applicable

Acknowledgments: The authors gratefully acknowledge the Deanship of Scientific no Research, King Khalid University (KKU), Abha-Asir, Kingdom of Saudi Arabia for funding this research work under the grant number GRP/93/42.

Conflicts of Interest: The authors declare no conflict of interest.

\section{References}

1. Yetisgin, A.A.; Cetinel, S.; Zuvin, M.; Kosar, A.; Kutlu, O. Therapeutic Nanoparticles and Their Targeted Delivery Applications. Molecules 2020, 25, 2193, doi:10.3390/molecules25092193.

2. Yadav, V.K.; Choudhary, N.; Khan, S.H.; Malik, P.; Inwati, G.K.; Suriyaprabha, R.; Ravi, R.K. Synthesis and Characterisation of Nano-Biosorbents and Their Applications for Waste Water Treatment. In Handbook of Research on Emerging Developments and Environmental Impacts of Ecological Chemistry; Gheorghe, D., Ashok, V., Eds.; IGI Global: Hershey, PA, USA, 2020; pp. $252-290$.

3. Patra, J.K.; Das, G.; Fraceto, L.F.; Campos, E.V.R.; del Pilar Rodriguez-Torres, M.; Acosta-Torres, L.S.; Diaz-Torres, L.A.; Grillo, R.; Swamy, M.K.; Sharma, S.; et al. Nano based drug delivery systems: recent developments and future prospects. J. Nanobiotechnol. 2018, 16, 71, doi:10.1186/s12951-018-0392-8.

4. Yadav, V.K.; Choudhary, N.; Khan, S.H.; Malik, P.; Inwati, G.K.; Suriyaprabha, R.; Ravi, R.K. Recovery of Natural Nanostructured Minerals: Ferrospheres, Plerospheres, Cenospheres, and Carbonaceous Particles From Fly Ash. In Handbook of Research on Emerging Developments and Environmental Impacts of Ecological Chemistry; Gheorghe, D., Ashok, V., Eds.; IGI Global: Hershey, PA, USA, 2020; pp. 450-470.

5. Patel, K.D.; Singh, R.K.; Kim, H.-W. Carbon-based nanomaterials as an emerging platform for theranostics. Mater. Horiz. 2019, 6, 434-469, doi:10.1039/c8mh00966j.

6. Hu, X.-L.; Shang, Y.; Yan, K.-C.; Sedgwick, A.C.; Gan, H.-Q.; Chen, G.-R.; He, X.-P.; James, T.D.; Chen, D. Low-dimensional nanomaterials for antibacterial applications. J. Mater. Chem. B 2021, 9, 3640-3661, doi:10.1039/d1tb00033k.

7. Gougoulias, C.; Clark, J.; Shaw, L. The role of soil microbes in the global carbon cycle: tracking the below-ground microbial processing of plant-derived carbon for manipulating carbon dynamics in agricultural systems. J. Sci. Food Agric. 2014, 94, 2362-2371, doi:10.1002/jsfa.6577.

8. Alam, J.; Yadav, V.K.; Yadav, K.K.; Cabral-Pinto, M.M.; Tavker, N.; Choudhary, N.; Shukla, A.K.; Ali, F.A.A.; Alhoshan, M.; Hamid, A.A. Recent Advances in Methods for the Recovery of Carbon Nanominerals and Polyaromatic Hydrocarbons from Coal Fly Ash and their Emerging Applications. Crystals 2021, 11, 88, doi:10.3390/cryst11020088.

9. Júnior, A.H.D.S.; Macuvele, D.L.P.; Riella, H.G.; Soares, C.; Padoin, N. Are carbon dots effective for ion sensing and antiviral applications? A state-of-the-art description from synthesis methods to cost evaluation. J. Mater. Res. Technol. 2021, 12, 688-716, doi:10.1016/j.jmrt.2021.02.069.

10. Yu, Z.; Li, Q.; Wang, J.; Yu, Y.; Wang, Y.; Zhou, Q.; Li, P. Reactive Oxygen Species-Related Nanoparticle Toxicity in the Biomedical Field. Nanoscale Res. Lett. 2020, 15, 115, doi:10.1186/s11671-020-03344-7.

11. Kou, X.; Jiang, S.; Park, S.-J.; Meng, L.-Y. A review: recent advances in preparations and applications of heteroatom-doped carbon quantum dots. Dalton Trans. 2020, 49, 6915-6938, doi:10.1039/d0dt01004a.

12. Doñate-Buendía, C.; Fernández-Alonso, M.; Lancis, J.; Mínguez-Vega, G. Pulsed laser ablation in liquids for the production of gold nanoparticles and carbon quantum dots: from plasmonic to fluorescence and cell labelling. J. Phys. Conf. Ser. 2020, 1537, 012013, doi:10.1088/1742-6596/1537/1/012013.

13. Elugoke, S.; Adekunle, A.; Fayemi, O.; Mamba, B.; Sherif, E.-S.; Ebenso, E. Carbon-Based Quantum Dots for Electrochemical Detection of Monoamine Neurotransmitters-Review. Biosensors 2020, 10, 162, doi:10.3390/bios10110162.

14. Kang, C.; Huang, Y.; Yang, H.; Yan, X.F.; Chen, Z.P. A Review of Carbon Dots Produced from Biomass Wastes. Nanomaterials 2020, 10, 2316, doi:10.3390/nano10112316.

15. Başoğlu, A.; Ocak, Ü.; Gümrükçüoğlu, A. Synthesis of Microwave-Assisted Fluorescence Carbon Quantum Dots Using RoastedChickpeas and its Applications for Sensitive and Selective Detection of Fe ${ }^{3+}$ Ions. J. Fluoresc. 2020, 30, 515-526, doi:10.1007/s10895019-02428-7.

16. Iravani, S.; Varma, R.S. Green synthesis, biomedical and biotechnological applications of carbon and graphene quantum dots. A review. Environ. Chem. Lett. 2020, 18, 703-727, doi:10.1007/s10311-020-00984-0. 
17. Sharma, A.; Das, J. Small molecules derived carbon dots: synthesis and applications in sensing, catalysis, imaging, and biomedicine. J. Nanobiotechnol. 2019, 17, 9, doi:10.1186/s12951-019-0525-8.

18. Dong, X.; Liang, W.; Meziani, M.J.; Sun, Y.-P.; Yang, L. Carbon Dots as Potent Antimicrobial Agents. Theranostics 2020, 10, 671686, doi:10.7150/thno.39863.

19. Gnanamoorthy, G.; Ahmed, E.M.; Yadav, V.K.; Narayanan, V. New modification of (Platinum aminophosphate) nanoparticles surface: Superior photocatalytic properties and antimicrobial applications. Curr. Res. Green Sustain. Chem. 2021, 4, 100148, doi:10.1016/j.crgsc.2021.100148.

20. Dong, Y.; Chang, Y.; Gao, H.; Anchustegui, V.A.L.; Yu, Q.; Wang, H.; Liu, J.-H.; Wang, S. Characteristic synergistic cytotoxic effects toward cells in graphene oxide dressing with cadmium and copper ions. Toxicol. Res. 2019, 8, 908-917, doi:10.1039/c9tx00146h. 21. Ruzycka-Ayoush, M.; Kowalik, P.; Kowalczyk, A.; Bujak, P.; Nowicka, A.M.; Wojewodzka, M. Quantum dots as targeted doxorubicin drug delivery nanosystems in human lung cancer cells. Cancer Nanotechnol. 2021, 12, 8.

22. Yang, C.; Zhang, G.; Feng, L.; Li, B.; Li, Z.; Chen, R.; Qin, C.; Gao, Y.; Xiao, L.; Jia, S. Suppressing the photobleaching and photoluminescence intermittency of single near-infrared CdSeTe/ZnS quantum dots with p-phenylenediamine. Opt. Express 2018, 26, 11889-11902, doi:10.1364/oe.26.011889.

23. Butera, E.; Zammataro, A.; Pappalardo, A.; Sfrazzetto, G.T. Supramolecular Sensing of Chemical Warfare Agents. ChemPlusChem 2021, 86, 681-695, doi:10.1002/cplu.202100071.

24. Paul, S.; Hazra, N.; Hazra, S.; Banerjee, A. Carbon dot mediated trihybrid formation by reduction of GO and in situ gold nanocluster fabrication: photo-switching behaviour and degradation of chemical warfare agent stimulants. J. Mater. Chem. C 2020, 8 , 15735-15741, doi:10.1039/d0tc03554h.

25. Song, Y.; Chen, J.; Hu, D.; Liu, F.; Li, P.; Li, H.; Chen, S.; Tan, H.; Wang, L. Ratiometric fluorescent detection of biomakers for biological warfare agents with carbon dots chelated europium-based nanoscale coordination polymers. Sens. Actuators B Chem. 2015, 221, 586-592, doi:10.1016/j.snb.2015.07.008.

26. Tuccitto, N.; Fichera, L.; Ruffino, R.; Cantaro, V.; Sfuncia, G.; Nicotra, G.; Sfrazzetto, G.T.; Li-Destri, G.; Valenti, A.; Licciardello, A.; et al. Carbon Quantum Dots as Fluorescence Nanochemosensors for Selective Detection of Amino Acids. ACS Appl. Nano Mater. 2021, 4, 6250-6256, doi:10.1021/acsanm.1c01046.

27. Kumar, D.; Kumar, I.; Chaturvedi, P.; Chouksey, A.; Tandon, R.; Chaudhury, P. Study of simultaneous reversible and irreversible adsorption on single-walled carbon nanotube gas sensor. Mater. Chem. Phys. 2016, 177, 276-282, doi:10.1016/j.matchemphys.2016.04.028.

28. Tuccitto, N.; Spitaleri, L.; Destri, G.L.; Pappalardo, A.; Gulino, A.; Sfrazzetto, G.T. Supramolecular Sensing of a Chemical Warfare Agents Simulant by Functionalized Carbon Nanoparticles. Molecules 2020, 25, 5731, doi:10.3390/molecules25235731.

29. Tisdale, W.; Zhu, X.-Y. Artificial atoms on semiconductor surfaces. Proc. Natl. Acad. Sci. USA 2011, 108, 965-970, doi:10.1073/pnas.1006665107.

30. Wang, Y.; Hu, A. Carbon quantum dots: synthesis, properties and applications. J. Mater. Chem. C 2014, 2, 6921-6939, doi:10.1039/c4tc00988f.

31. Pang, H.; Cao, X.; Zhu, L.; Zheng, M. Synthesis of Functional Nanomaterials for Electrochemical Energy Storage; Springer Science and Business Media LLC: Berlin/Heidelberg, Germany, 2020; pp. 13-29;.

32. Kingston, C.T.; Simard, B. Fabrication of Carbon Nanotubes. Anal. Lett. 2003, 36, 3119-3145.

33. Sun, Y.; Wang, S.; Li, C.; Luo, P.; Tao, L.; Wei, Y.; Shi, G. Large scale preparation of graphene quantum dots from graphite with tunable fluorescence properties. Phys. Chem. Chem. Phys. 2013, 15, 9907-9913, doi:10.1039/c3cp50691f.

34. Wolfbeis, O.S. An overview of nanoparticles commonly used in fluorescent bioimaging. Chem. Soc. Rev. 2015, 44, 4743-4768, doi:10.1039/c4cs00392f.

35. Petryayeva, E.; Algar, W.R.; Medintz, I.L. Quantum Dots in Bioanalysis: A Review of Applications across Various Platforms for Fluorescence Spectroscopy and Imaging. Appl. Spectrosc. 2013, 67, 215-252, doi:10.1366/12-06948.

36. Wu, Y.; Ren, Y.; Guo, J.; Liu, Z.; Liu, L.; Yan, F. Imidazolium-type ionic liquid-based carbon quantum dot doped gels for information encryption. Nanoscale 2020, 12, 20965-20972, doi:10.1039/d0nr06358d.

37. Lu, Y.; Huang, G.; Wang, S.; Mi, C.; Wei, S.; Tian, F.; Li, W.; Cao, H.; Cheng, Y. A review on diamond-like carbon films grown by pulsed laser deposition. Appl. Surf. Sci. 2021, 541, 148573, doi:10.1016/j.apsusc.2020.148573.

38. Reyes, D.; Camacho, M.; Camacho, M.; Mayorga, M.; Weathers, D.; Salamo, G.; Wang, Z.; Neogi, A. Laser Ablated Carbon Nanodots for Light Emission. Nanoscale Res. Lett. 2016, 11, 424, doi:10.1186/s11671-016-1638-8.

39. Liu, J.; Li, R.; Yang, B. Carbon Dots: A New Type of Carbon-Based Nanomaterial with Wide Applications. ACS Central Sci. 2020, 6, 2179-2195, doi:10.1021/acscentsci.0c01306.

40. Calabro, R.; Yang, D.-S.; Kim, D.Y. Liquid-phase laser ablation synthesis of graphene quantum dots from carbon nano-onions: Comparison with chemical oxidation. J. Colloid Interface Sci. 2018, 527, 132-140, doi:10.1016/j.jcis.2018.04.113.

41. Molaei, M.J. Carbon quantum dots and their biomedical and therapeutic applications: a review. RSC Adv. 2019, 9, 6460-6481, doi:10.1039/c8ra08088g.

42. Kaczmarek, A.; Hoffman, J.; Morgiel, J.; Mościcki, T.; Stobiński, L.; Szymański, Z.; Małolepszy, A. Luminescent Carbon Dots Synthesized by the Laser Ablation of Graphite in Polyethylenimine and Ethylenediamine. Materials 2021, 14, 729, doi:10.3390/ma14040729.

43. Małolepszy, A.; Blonski, S.; Chrzanowska-Giżyńska, J.; Wojasiński, M.; Plocinski, T.; Stobinski, L.; Szymanski, Z. Fluorescent carbon and graphene oxide nanoparticles synthesized by the laser ablation in liquid. Appl. Phys. A 2018, 124, 282, doi:10.1007/s00339018-1711-5. 
44. Gonçalves, H.; Duarte, A.J.; da Silva, J.C.E. Optical fiber sensor for $\mathrm{Hg}(\mathrm{II})$ based on carbon dots. Biosens. Bioelectron. 2010, 26, 1302-1306, doi:10.1016/j.bios.2010.07.018.

45. Nguyen, V.; Zhao, N.; Yan, L.; Zhong, P.; Le, P.H. Double-pulse femtosecond laser ablation for synthesis of ultrasmall carbon nanodots. Mater. Res. Express 2020, 7, 015606.

46. Thongpool, V.; Asanithi, P.; Limsuwan, P. Synthesis of Carbon Particles using Laser Ablation in Ethanol. Procedia Eng. 2012, 32, 1054-1060, doi:10.1016/j.proeng.2012.02.054.

47. Zuo, P.; Lu, X.; Sun, Z.; Guo, Y.; He, H. A review on syntheses, properties, characterization and bioanalytical applications of fluorescent carbon dots. Microchim. Acta 2015, 183, 519-542, doi:10.1007/s00604-015-1705-3.

48. Guili Ge, Lin Li, Dan Wang, Mingjian Chen, Zhaoyang Zeng, Wei Xiong, Xu Wu and Can Guo. Carbon dots: synthesis, properties and biomedical applications. J. Mater. Chem. B, 2021, Advance Article. doi.org/10.1039/D1TB01077H

49. Varenikov, A.; Shapiro, E.; Gandelman, M. Decarboxylative Halogenation of Organic Compounds. Chem. Rev. 2021, 121, 412484, doi:10.1021/acs.chemrev.0c00813.

50. Bottini, M.; Tautz, L.; Huynh, H.; Monosov, E.; Bottini, N.; Dawson, M.I.; Bellucci, S.; Mustelin, T. Covalent decoration of multiwalled carbon nanotubes with silica nanoparticles. Chem. Commun. 2005, 2005, 758-760, doi:10.1039/b412876a.

51. Michelsen, H.A.; Colket, M.B.; Bengtsson, P.-E.; D’Anna, A.; Desgroux, P.; Haynes, B.S.; Miller, J.H.; Nathan, G.J.; Pitsch, H.; Wang, H. A Review of Terminology Used to Describe Soot Formation and Evolution under Combustion and Pyrolytic Conditions. ACS Nano 2020, 14, 12470-12490, doi:10.1021/acsnano.0c06226.

52. Su, Y.; Xie, M.; Lu, X.; Wei, H.; Geng, H.; Yang, Z.; Zhang, Y. Facile synthesis and photoelectric properties of carbon dots with upconversion fluorescence using arc-synthesized carbon by-products. RSC Adv. 2013, 4, 4839-4842, doi:10.1039/c3ra45453c.

53. Biazar, N.; Poursalehi, R.; Delavari, H. Optical and structural properties of carbon dots/TiO2 nanostructures prepared via DC arc discharge in liquid. In Proceedings of the 6th International Biennial Conference on Ultrafine Grained and Nanostructured Materials: (UFGNSM2017), Kish Island, Iran, 12-13 November 2017.

54. Dey, S.; Govindaraj, A.; Biswas, K.; Rao, C.N.R. Luminescence properties of boron and nitrogen doped graphene quantum dots prepared from arc-discharge-generated doped graphene samples. Chem. Phys. Lett. 2014, 595-596, 203-208, doi:10.1016/j.cplett.2014.02.012.

55. Fang, S.; Lin, Y.; Hu, Y.H. Recent Advances in Green, Safe, and Fast Production of Graphene Oxide via Electrochemical Approaches. ACS Sustain. Chem. Eng. 2019, 7, 12671-12681, doi:10.1021/acssuschemeng.9b02794.

56. Pender, J.P.; Jha, G.; Youn, D.H.; Ziegler, J.M.; Andoni, I.; Choi, E.; Heller, A.; Dunn, B.S.; Weiss, P.S.; Penner, R.M.; et al. Electrode Degradation in Lithium-Ion Batteries. ACS Nano 2020, 14, 1243-1295, doi:10.1021/acsnano.9b04365.

57. Wang, B.; Tan, H.; Zhang, T.; Duan, W.; Zhu, Y. Hydrothermal synthesis of N-doped carbon dots from an ethanolamine-ionic liquid gel to construct label-free multifunctional fluorescent probes for $\mathrm{Hg}^{2+}, \mathrm{Cu}^{2+}$ and $\mathrm{S}_{2} \mathrm{O}_{3}{ }^{2-}$. Analyst 2019, 144, 3013-3022, doi:10.1039/c9an00116f.

58. Qin, K.; Zhang, D.; Ding, Y.; Zheng, X.; Xiang, Y.; Hua, J.; Zhang, Q.; Ji, X.; Li, B.; Wei, Y. Applications of hydrothermal synthesis of Escherichia coli derived carbon dots in in vitro and in vivo imaging and p-nitrophenol detection. Analyst 2019, 145, 177-183, doi:10.1039/c9an01753d.

59. Edison, T.N.J.I.; Atchudan, R.; Sethuraman, M.G.; Shim, J.-J.; Lee, Y.R. Microwave assisted green synthesis of fluorescent Ndoped carbon dots: Cytotoxicity and bio-imaging applications. J. Photochem. Photobiol. B Biol. 2016, 161, 154-161, doi:10.1016/j.jphotobiol.2016.05.017.

60. Wu, Z.L.; Zhang, P.; Gao, M.X.; Liu, C.F.; Wang, W.; Leng, F.; Huang, C.Z. One-pot hydrothermal synthesis of highly luminescent nitrogen-doped amphoteric carbon dots for bioimaging from Bombyx mori silk-natural proteins. J. Mater. Chem. B 2013, 1, 2868-2873, doi:10.1039/c3tb20418a.

61. Zhang, Y.; Cui, P.; Zhang, F.; Feng, X.; Wang, Y.; Yang, Y.; Liu, X. Fluorescent probes for "off-on" highly sensitive detection of $\mathrm{Hg}^{2+}$ and L-cysteine based on nitrogen-doped carbon dots. Talanta 2016, 152, 288-300.

62. Hou, Y.; Lu, Q.; Deng, J.; Li, H.; Zhang, Y. One-pot electrochemical synthesis of functionalized fluorescent carbon dots and their selective sensing for mercury ion. Anal. Chim. Acta 2015, 866, 69-74, doi:10.1016/j.aca.2015.01.039.

63. Baluta, S.; Lesiak, A.; Cabaj, J. Simple and Cost-Effective Electrochemical Method for Norepinephrine Determination Based on Carbon Dots and Tyrosinase. Sensors 2020, 20, 4567, doi:10.3390/s20164567.

64. Shinde, D.B.; Pillai, V.K. Electrochemical Preparation of Luminescent Graphene Quantum Dots from Multiwalled Carbon Nanotubes. Chem. A Eur. J. 2012, 18, 12522-12528, doi:10.1002/chem.201201043.

65. Huang, Q.; Hu, S.; Zhang, H.; Chen, J.; He, Y.; Li, F.; Weng, W.; Ni, J.; Bao, X.; Lin, Y. Carbon dots and chitosan composite film based biosensor for the sensitive and selective determination of dopamine. Analyst 2013, 138, 5417-5423, doi:10.1039/c3an00510k.

66. Yang, L.; Huang, N.; Lu, Q.; Liu, M.; Li, H.; Zhang, Y.; Yao, S. A quadruplet electrochemical platform for ultrasensitive and simultaneous detection of ascorbic acid, dopamine, uric acid and acetaminophen based on a ferrocene derivative functional Au NPs/carbon dots nanocomposite and graphene. Anal. Chim. Acta 2016, 903, 69-80, doi:10.1016/j.aca.2015.11.021.

67. Zhu, W.; Zhou, Y.; Tao, M.; Yan, X.; Liu, Y.; Zhou, X. An electrochemical and fluorescence dual-signal assay based on $\mathrm{Fe}_{3} \mathrm{O}_{4} @ \mathrm{MnO}_{2}$ and N-doped carbon dots for determination of hydrogen peroxide. Microchim. Acta 2020, 187, 187, doi:10.1007/s00604020-4163-5.

68. Ng, H.M.; Lim, G.; Leo, C. Comparison between hydrothermal and microwave-assisted synthesis of carbon dots from biowaste and chemical for heavy metal detection: A review. Microchem. J. 2021, 165, 106116, doi:10.1016/j.microc.2021.106116.

69. Zhu, S.; Meng, Q.; Wang, L.; Zhang, J.; Song, Y.; Jin, H.; Yang, B. Highly Photoluminescent Carbon Dots for Multicolor Patterning, Sensors, and Bioimaging. Angew. Chem. 2013, 52, 3953-3957. 
70. Stefanakis, D.; Philippidis, A.; Sygellou, L.; Filippidis, G.; Ghanotakis, D.; Anglos, D. Synthesis of fluorescent carbon dots by a microwave heating process: structural characterization and cell imaging applications. J. Nanoparticle Res. 2014, 16, 2646, doi:10.1007/s11051-014-2646-1.

71. Liu, C.; Zhang, P.; Tian, F.; Li, W.; Li, F.; Liu, W. One-step synthesis of surface passivated carbon nanodots by microwave assisted pyrolysis for enhanced multicolor photoluminescence and bioimaging. J. Mater. Chem. 2011, 21, 13163-13167, doi:10.1039/c1jm12744f.

72. Kiran, S.; Misra, R.D.K. Mechanism of intracellular detection of glucose through nonenzymatic and boronic acid functionalized carbon dots. J. Biomed. Mater. Res. Part A 2015, 103, 2888-2897, doi:10.1002/jbm.a.35421.

73. Song, Y.; Zhu, S.; Zhang, S.; Fu, Y.; Wang, L.; Zhao, X.; Yang, B. Investigation from chemical structure to photoluminescent mechanism: a type of carbon dots from the pyrolysis of citric acid and an amine. J. Mater. Chem. C 2015, 3, 5976-5984, doi:10.1039/c5tc00813a.

74. Liu, M.L.; Bin Chen, B.; Li, C.M.; Huang, C.Z. Carbon dots: Synthesis, formation mechanism, fluorescence origin and sensing applications. Green Chem. 2019, 21, 449-471, doi:10.1039/c8gc02736f.

75. Cao, X.; Wang, J.; Deng, W.; Chen, J.; Wang, Y.; Zhou, J.; Du, P.; Xu, W.; Wang, Q.; Wang, Q.; et al. Photoluminescent Cationic Carbon Dots as efficient Non-Viral Delivery of Plasmid SOX9 and Chondrogenesis of Fibroblasts. Sci. Rep. 2018, 8, 7057, doi:10.1038/s41598-018-25330-x.

76. Gong, N.; Wang, H.; Li, S.; Deng, Y.; Chen, X.; Ye, L.; Gu, W. Microwave-Assisted Polyol Synthesis of Gadolinium-Doped Green Luminescent Carbon Dots as a Bimodal Nanoprobe. Langmuir 2014, 30, 10933-10939, doi:10.1021/la502705g.

77. Sarkar, T.; Bohidar, H.; Solanki, P.R. Carbon dots-modified chitosan based electrochemical biosensing platform for detection of vitamin D. Int. J. Biol. Macromol. 2018, 109, 687-697, doi:10.1016/j.ijbiomac.2017.12.122.

78. Li, H.; Shao, F.-Q.; Zou, S.-Y.; Yang, Q.-J.; Huang, H.; Feng, J.-J.; Wang, A.-J. Microwave-assisted synthesis of N,P-doped carbon dots for fluorescent cell imaging. Microchim. Acta 2015, 183, 821-826, doi:10.1007/s00604-015-1714-2.

79. Tabaraki, R.; Sadeghinejad, N. Microwave assisted synthesis of doped carbon dots and their application as green and simple turn off-on fluorescent sensor for mercury (II) and iodide in environmental samples. Ecotoxicol. Environ. Saf. 2018, 153, 101-106, doi:10.1016/j.ecoenv.2018.01.059.

80. Romero MP, Alves F, Stringasci MD, Buzzá HH, Ciol H, Inada NM and Bagnato VS (2021) One-Pot Microwave-Assisted Synthesis of Carbon Dots and in vivo and in vitro Antimicrobial Photodynamic Applications. Front. Microbiol. 12:662149. doi: 10.3389/fmicb.2021.662149.

81. López, C.; Zougagh, M.; Algarra, M.; Rodriguez-Castellon, E.; Campos, B.; da Silva, J.E.; Jiménez, J.J.; Ríos, Á. Microwave-assisted synthesis of carbon dots and its potential as analysis of four heterocyclic aromatic amines. Talanta 2015, 132, 845-850, doi:10.1016/j.talanta.2014.10.008.

82. Pajewska-Szmyt, M.; Buszewski, B.; Gadzała-Kopciuch, R. Sulphur and nitrogen doped carbon dots synthesis by microwave assisted method as quantitative analytical nano-tool for mercury ion sensing. Mater. Chem. Phys. 2020, 242, 122484, doi:10.1016/j.matchemphys.2019.122484.

83. Zhao, C.; Li, X.; Cheng, C.; Yang, Y. Green and microwave-assisted synthesis of carbon dots and application for visual detection of cobalt(II) ions and pH sensing. Microchem. J. 2019, 147, 183-190, doi:10.1016/j.microc.2019.03.029.

84. Yaashikaa, P.; Kumar, P.S.; Varjani, S.; Saravanan, A. A critical review on the biochar production techniques, characterization, stability and applications for circular bioeconomy. Biotechnol. Rep. 2020, 28, e00570, doi:10.1016/j.btre.2020.e00570.

85. Wang, N.; Koh, S.; Jeong, B.G.; Lee, D.; Kim, W.D.; Park, K.; Nam, M.K.; Lee, K.; Kim, Y.; Lee, B.-H.; et al. Highly luminescent silica-coated CdS/CdSe/CdS nanoparticles with strong chemical robustness and excellent thermal stability. Nanotechnology 2017, 28, 185603, doi:10.1088/1361-6528/aa6828.

86. Fang, J.; Xie, Z.; Wallace, G.; Wang, X. Co-deposition of carbon dots and reduced graphene oxide nanosheets on carbon-fiber microelectrode surface for selective detection of dopamine. Appl. Surf. Sci. 2017, 412, 131-137, doi:10.1016/j.apsusc.2017.03.257.

87. Guo, F.; Shi, W.; Guan, W.; Huang, H.; Liu, Y. Carbon dots/g-C3N4/ZnO nanocomposite as efficient visible-light driven photocatalyst for tetracycline total degradation. Sep. Purif. Technol. 2017, 173, 295-303, doi:10.1016/j.seppur.2016.09.040.

88. Armano, A.; Buscarino, G.; Messina, F.; Sciortino, A.; Cannas, M.; Gelardi, F.M.; Giannazzo, F.; Schilirò, E.; Agnello, S. Dy namic Modification of Fermi Energy in Single-Layer Graphene by Photoinduced Electron Transfer from Carbon Dots. Nanomaterials 2020, 10, 528, doi:10.3390/nano10030528.

89. Du, F.; Zhang, L.; Zhang, L.; Zhang, M.; Gong, A.; Tan, Y.; Miao, J.; Gong, Y.; Sun, M.; Ju, H.; et al. Engineered gadolinium-doped carbon dots for magnetic resonance imaging-guided radiotherapy of tumors. Biomaterials 2017, 121, 109-120, doi:10.1016/j.biomaterials.2016.07.008.

90. Wang, F.; Xie, Z.; Zhang, H.; Liu, C.-Y.; Zhang, Y.-G. Highly Luminescent Organosilane-Functionalized Carbon Dots. Adv. Funct. Mater. 2011, 21, 1027-1031, doi:10.1002/adfm.201002279.

91. Wang, S.; Chen, Z.-G.; Cole, I.; Li, Q. Structural evolution of graphene quantum dots during thermal decomposition of citric acid and the corresponding photoluminescence. Carbon 2015, 82, 304-313, doi:10.1016/j.carbon.2014.10.075.

92. Wan, J.-Y.; Yang, Z.; Liu, Z.-G.; Wang, H.-X. Ionic liquid-assisted thermal decomposition synthesis of carbon dots and graphenelike carbon sheets for optoelectronic application. RSC Adv. 2016, 6, 61292-61300, doi:10.1039/c6ra14181a.

93. Hou, J.; Wang, W.; Zhou, T.; Wang, B.; Li, H.; Ding, L. Synthesis and formation mechanistic investigation of nitrogen-doped carbon dots with high quantum yields and yellowish-green fluorescence. Nanoscale 2016, 8, 11185-11193, doi:10.1039/c6nr02701f.

94. Wei, Z.; Wang, B.; Liu, Y.; Liu, Z.; Zhang, H.; Zhang, S.; Chang, J.; Lu, S. Green synthesis of nitrogen and sulfur co-doped carbon dots from Allium fistulosum for cell imaging. New J. Chem. 2019, 43, 718-723, doi:10.1039/c8nj05783d.

95. Dolai, S.; Bhunia, S.K.; Jelinek, R. Carbon-dot-aerogel sensor for aromatic volatile organic compounds. Sensors Actuators B Chem. 2017, 241, 607-613, doi:10.1016/j.snb.2016.10.124. 
96. Lin, H.; Huang, J.; Ding, L. Preparation of Carbon Dots with High-Fluorescence Quantum Yield and Their Application in Dopamine Fluorescence Probe and Cellular Imaging. J. Nanomater. 2019, 2019, 5037243, doi:10.1155/2019/5037243.

97. Wang, J.; Wei, J.; Su, S.; Qiu, J. Novel fluorescence resonance energy transfer optical sensors for vitamin B12 detection using thermally reduced carbon dots. New J. Chem. 2015, 39, 501-507, doi:10.1039/c4nj00538d.

98. Ma, C.; Yin, C.; Fan, Y.; Yang, X.; Zhou, X. Highly efficient synthesis of N-doped carbon dots with excellent stability through pyrolysis method. J. Mater. Sci. 2019, 54, 9372-9384, doi:10.1007/s10853-019-03585-7.

99. Bourlinos, A.B.; Bakandritsos, A.; Kouloumpis, A.; Gournis, D.; Krysmann, M.; Giannelis, E.P.; Polakova, K.; Safarova, K.; Hola, K.; Zboril, R. Gd(iii)-doped carbon dots as a dual fluorescent-MRI probe. J. Mater. Chem. 2012, 22, 23327-23330, doi:10.1039/c2jm35592b.

100. Sciortino, A.; Cannizzo, A.; Messina, F. Carbon Nanodots: A Review-From the Current Understanding of the Fundamental Photophysics to the Full Control of the Optical Response. J. Carbon Res. 2018, 4, 67, doi:10.3390/c4040067.

101. Feng, T.; Ai, X.; An, G.; Yang, P.; Zhao, Y. Charge-Convertible Carbon Dots for Imaging-Guided Drug Delivery with Enhanced in Vivo Cancer Therapeutic Efficiency. ACS Nano 2016, 10, 4410-4420, doi:10.1021/acsnano.6b00043.

102. Zheng, M.; Ruan, S.; Liu, S.; Sun, T.; Qu, D.; Zhao, H.; Xie, Z.; Gao, H.; Jing, X.; Sun, Z. Self-Targeting Fluorescent Carbon Dots for Diagnosis of Brain Cancer Cells. ACS Nano 2015, 9, 11455-11461, doi:10.1021/acsnano.5b05575.

103. Dong, Y.; Pang, H.; Bin Yang, H.; Guo, C.; Shao, J.; Chi, Y.; Li, C.M.; Yu, T. Carbon-Based Dots Co-doped with Nitrogen and Sulfur for High Quantum Yield and Excitation-Independent Emission. Angew. Chem. Int. Ed. 2013, 52, 7800-7804, doi:10.1002/anie.201301114.

104. Qian, Z.; Shan, X.; Chai, L.; Ma, J.; Chen, J.; Feng, H. Si-Doped Carbon Quantum Dots: A Facile and General Preparation Strategy, Bioimaging Application, and Multifunctional Sensor. ACS Appl. Mater. Interfaces 2014, 6, 6797-6805, doi:10.1021/am500403n.

105. John, T.S.; Yadav, P.K.; Kumar, D.; Singh, S.K.; Hasan, S.H. Highly fluorescent carbon dots from wheat bran as a novel drug delivery system for bacterial inhibition. Luminescence 2020, 35, 913-923, doi:10.1002/bio.3801.

106. Xu, J.; Wang, C.; Li, H.; Zhao, W. Synthesis of green-emitting carbon quantum dots with double carbon sources and their application as a fluorescent probe for selective detection of $\mathrm{Cu}^{2+}$ ions. RSC Adv. 2020, 10, 2536-2544, doi:10.1039/c9ra08654d.

107. Prasannan, A.; Imae, T. One-Pot Synthesis of Fluorescent Carbon Dots from Orange Waste Peels. Ind. Eng. Chem. Res. 2013, 52, 15673-15678, doi:10.1021/ie402421s.

108. Liu, Y.; Zhao, Y.; Zhang, Y. One-step green synthesized fluorescent carbon nanodots from bamboo leaves for copper (II) ion detection. Sensors Actuators B Chem. 2014, 196, 647-652, doi:10.1016/j.snb.2014.02.053.

109. Tyagi, A.; Tripathi, K.; Singh, N.; Choudhary, S.; Gupta, R.K. Green synthesis of carbon quantum dots from lemon peel waste: applications in sensing and photocatalysis. RSC Adv. 2016, 6, 72423-72432, doi:10.1039/c6ra10488f.

110. Chunduri, L.A.A.; Kurdekar, A.; Patnaik, S.; Dev, B.V.; Rattan, T.M.; Kamisetti, V. Carbon Quantum Dots from Coconut Husk: Evaluation for Antioxidant and Cytotoxic Activity. Mater. Focus 2016, 5, 55-61, doi:10.1166/mat.2016.1289.

111. Zhang, H.; Kang, S.; Wang, G.; Zhang, Y.; Zhao, H. Fluorescence Determination of Nitrite in Water Using Prawn-Shell Derived Nitrogen-Doped Carbon Nanodots as Fluorophores. ACS Sens. 2016, 1, 875-881, doi:10.1021/acssensors.6b00269.

112. Yuan, M.; Zhong, R.; Gao, H.; Li, W.; Yun, X.; Liu, J.; Zhao, X.; Zhao, G.; Zhang, F. One-step, green, and economic synthesis of water-soluble photoluminescent carbon dots by hydrothermal treatment of wheat straw, and their bio-applications in labeling, imaging, and sensing. Appl. Surf. Sci. 2015, 355, 1136-1144, doi:10.1016/j.apsusc.2015.07.095.

113. Shan, X.; Chai, L.; Ma, J.; Qian, Z.; Chen, J.; Feng, H. B-doped carbon quantum dots as a sensitive fluorescence probe for hydrogen peroxide and glucose detection. Analyst 2014, 139, 2322-2325, doi:10.1039/c3an02222f.

114. Qin, X.; Lu, W.; Asiri, A.M.; Al-Youbi, A.O.; Sun, X. Green, low-cost synthesis of photoluminescent carbon dots by hydrothermal treatment of willow bark and their application as an effective photocatalyst for fabricating Au nanoparticles-reduced graphene oxide nanocomposites for glucose detection. Catal. Sci. Technol. 2013, 3, 1027, doi:10.1039/c2cy20635h.

115. Kumar, R.; Kumar, V.B.; Gedanken, A. Sonochemical synthesis of carbon dots, mechanism, effect of parameters, and catalytic, energy, biomedical and tissue engineering applications. Ultrason. Sonochem. 2020, 64, 105009, doi:10.1016/j.ultsonch.2020.105009.

116. Zhang, Y.; Park, M.; Kim, H.Y.; Ding, B.; Park, S.-J. A facile ultrasonic-assisted fabrication of nitrogen-doped carbon dots/BiOBr up-conversion nanocomposites for visible light photocatalytic enhancements. Sci. Rep. 2017, 7, 45086, doi:10.1038/srep45086.

117. Li, H.; He, X.; Liu, Y.; Huang, H.; Lian, S.; Lee, S.-T.; Kang, Z. One-step ultrasonic synthesis of water-soluble carbon nanoparticles with excellent photoluminescent properties. Carbon 2011, 49, 605-609, doi:10.1016/j.carbon.2010.10.004.

118. Pan, M.; Xie, X.; Liu, K.; Yang, J.; Hong, L.; Wang, S. Fluorescent Carbon Quantum Dots-Synthesis, Functionalization and Sensing Application in FoodAnalysis. Nanomaterials 2020, 10, 25.

119. Huang, H.; Cui, Y.; Liu, M.; Chen, J.; Wan, Q.; Wen, Y.; Deng, F.; Zhou, N.; Zhang, X.; Wei, Y. A one-step ultrasonic irradiation assisted strategy for the preparation of polymer-functionalized carbon quantum dots and their biological imaging. J. Colloid Interface Sci. 2018, 532, 767-773, doi:10.1016/j.jcis.2018.07.099.

120. Lu, M.; Zhou, L. One-step sonochemical synthesis of versatile nitrogen-doped carbon quantum dots for sensitive detection of Fe2+ ions and temperature in vitro. Mater. Sci. Eng. C 2019, 101, 352-359, doi:10.1016/j.msec.2019.03.109.

121. Li, H.; He, X.; Liu, Y.; Yu, H.; Kang, Z.; Lee, S.-T. Synthesis of fluorescent carbon nanoparticles directly from active carbon via a one-step ultrasonic treatment. Mater. Res. Bull. 2011, 46, 147-151, doi:10.1016/j.materresbull.2010.10.013.

122. Tajik, S.; Dourandish, Z.; Zhang, K.; Beitollahi, H.; Van Le, Q.; Jang, H.W.; Shokouhimehr, M. Carbon and graphene quantum dots: a review on syntheses, characterization, biological and sensing applications for neurotransmitter determination. RSC Adv. 2020, 10, 15406-15429, doi:10.1039/d0ra00799d.

123. Das, S.; Ngashangva, L.; Goswami, P. Carbon Dots: An Emerging Smart Material for Analytical Applications. Micromachines 2021, 12, 84, doi:10.3390/mi12010084. 
124. Sun, X.; Liu, Y.; Niu, N.; Chen, L. Synthesis of molecularly imprinted fluorescent probe based on biomass-derived carbon quantum dots for detection of mesotrione. Anal. Bioanal. Chem. 2019, 411, 5519-5530, doi:10.1007/s00216-019-01930-y.

125. Demchenko, A.P. Excitons in Carbonic Nanostructures. C 2019, 5, 71, doi:10.3390/c5040071.

126. Roy, P.; Chen, P.-C.; Periasamy, A.P.; Chen, Y.-N.; Chang, H.-T. Photoluminescent carbon nanodots: synthesis, physicochemical properties and analytical applications. Mater. Today 2015, 18, 447-458, doi:10.1016/j.mattod.2015.04.005.

127. Zhu, S.; Song, Y.; Zhao, X.; Shao, J.; Zhang, J.; Yang, B. The photoluminescence mechanism in carbon dots (graphene quantum dots, carbon nanodots, and polymer dots): current state and future perspective. Nano Res. 2015, 8, 355-381, doi:10.1007/s12274-0140644-3.

128. Carbonaro, C.M.; Corpino, R.; Salis, M.; Mocci, F.; Thakkar, S.V.; Olla, C.; Ricci, P.C. On the Emission Properties of Carbon Dots: Reviewing Data and Discussing Models. C 2019, 5, 60.

129. He, M.; Zhang, J.; Wang, H.; Kong, Y.; Xiao, Y.; Xu, W. Material and Optical Properties of Fluorescent Carbon Quantum Dots Fabricated from Lemon Juice via Hydrothermal Reaction. Nanoscale Res. Lett. 2018, 13, 175, doi:10.1186/s11671-018-2581-7.

130. Wu, Z.L.; Liu, Z.X.; Yuan, Y.H. Carbon dots: materials, synthesis, properties and approaches to long-wavelength and multicolor emission. J. Mater. Chem. B 2017, 5, 3794-3809, doi:10.1039/c7tb00363c.

131. Slimane, A.B.; Najar, A.; Elafandy, R.; San-Román-Alerigi, D.P.; Anjum, D.; Ng, T.K.; Ooi, B.S. On the phenomenon of large photoluminescence red shift in GaN nanoparticles. Nanoscale Res. Lett. 2013, 8, 342.

132. Tian, P.; Tang, L.; Teng, K.; Lau, S. Graphene quantum dots from chemistry to applications. Mater. Today Chem. 2018, 10, 221258, doi:10.1016/j.mtchem.2018.09.007.

133. Fu, M.; Ehrat, F.; Wang, Y.; Milowska, K.; Reckmeier, C.J.; Rogach, A.L.; Stolarczyk, J.; Urban, A.; Feldmann, J. Carbon Dots: A Unique Fluorescent Cocktail of Polycyclic Aromatic Hydrocarbons. Nano Lett. 2015, 15, 6030-6035, doi:10.1021/acs.nanolett.5b02215. 134. Ruprecht, V.; Wieser, S.; Marguet, D.; Schütz, G.J. Spot Variation Fluorescence Correlation Spectroscopy Allows for Superresolution Chronoscopy of Confinement Times in Membranes. Biophys. J. 2011, 100, 2839-2845, doi:10.1016/j.bpj.2011.04.035.

135. Papaioannou, N.; Marinovic, A.; Yoshizawa, N.; Goode, A.E.; Fay, M.; Khlobystov, A.; Titirici, M.-M.; Sapelkin, A. Structure and solvents effects on the optical properties of sugar-derived carbon nanodots. Sci. Rep. 2018, 8, 6559, doi:10.1038/s41598-018-25012-8.

136. Zhu, S.; Wang, L.; Zhou, N.; Zhao, X.; Song, Y.; Maharjan, S.; Zhang, J.; Lu, L.; Wang, H.; Yang, B. The crosslink enhanced emission (CEE) in non-conjugated polymer dots: from the photoluminescence mechanism to the cellular uptake mechanism and internalization. Chem. Commun. 2014, 50, 13845-13848, doi:10.1039/c4cc05806b.

137. Hu, Y.; Yang, J.; Tian, J.; Jia, L.; Yu, J.S. Waste frying oil as a precursor for one-step synthesis of sulfur-doped carbon dots with pH-sensitive photoluminescence. Carbon 2014, 77, 775-782.

138. Sun, Y.; Shen, C.; Wang, J.; Lu, Y. Facile synthesis of biocompatible N, S-doped carbon dots for cell imaging and ion detecting. RSC Adv. 2015, 5, 16368-16375, doi:10.1039/C4RA13820A.

139. Varisco, M.; Zufferey, D.; Ruggi, A.; Zhang, Y.; Erni, R.; Mamula, O. Synthesis of hydrophilic and hydrophobic carbon quantum dots from waste of wine fermentation. R. Soc. Open Sci. 2017, 4, 170900, doi:10.1098/rsos.170900.

140. El-Shabasy, R.M.; Elsadek, M.F.; Ahmed, B.M.; Farahat, M.F.; Mosleh, K.M.; Taher, M.M. Recent Developments in Carbon Quantum Dots: Properties, Fabrication Techniques, and Bio-Applications. Processes 2021, 9, 388.

141. Bandi, R.; Gangapuram, B.R.; Dadigala, R.; Eslavath, R.; Singh, S.S.; Guttena, V. Facile and green synthesis of fluorescent carbon dots from onion waste and their potential applications as sensor and multicolour imaging agents. RSC Adv. 2016, 6, 28633-28639, doi:10.1039/c6ra01669c.

142. do D'Angelis, E.S.; Barbosa, C. Carbon Dots (C-dots) from Cow Manure with Impressive Subcellular Selectivity Tuned by Simple Chemical Modification. Chem. A Eur. J. 2015, 21, 5055-5060.

143. Atchudan, R.; Edison, T.N.J.I.; Shanmugam, M.; Perumal, S.; Somanathan, T.; Lee, Y.R. Sustainable synthesis of carbon quantum dots from banana peel waste using hydrothermal process for in vivo bioimaging. Phys. E Low Dimens. Syst. Nanostruct. 2021, 126, 114417, doi:10.1016/j.physe.2020.114417.

144. Cheng, C.; Shi, Y.; Li, M.; Xing, M.; Wu, Q. Carbon quantum dots from carbonized walnut shells: Structural evolution, fluorescence characteristics, and intracellular bioimaging. Mater. Sci. Eng. C 2017, 79, 473-480, doi:10.1016/j.msec.2017.05.094.

145. Xu-Cheng, F.; Xuan-Hua, L.; Jin, J.-Z.; Zhang, J.; Wei, G. Facile synthesis of bagasse waste derived carbon dots for trace mercury detection. Mater. Res. Express 2018, 5, 065044, doi:10.1088/2053-1591/aaccb7.

146. Issa, M.A.; Abidin, Z.Z.; Sobri, S.; Rashid, S.; Mahdi, M.A.; Ibrahim, N.A.; Pudza, M.Y. Facile Synthesis of Nitrogen-Doped Carbon Dots from Lignocellulosic Waste. Nanomaterials 2019, 9, 1500, doi:10.3390/nano9101500.

147. Xiao-Yan, W.; Xue-Yan, H.; Tian-Qi, W.; Xu-Cheng, F. Crown daisy leaf waste-derived carbon dots: A simple and green fluorescent probe for copper ion. Surf. Interface Anal. 2019, 52, 148-155, doi:10.1002/sia.6733.

148. Godavarthi, S.; Kumar, K.M.; Vélez, E.V.; Hernandez-Eligio, A.; Mahendhiran, M.; Hernandez-Como, N.; Aleman, M.; Gomez, L.M. Nitrogen doped carbon dots derived from Sargassum fluitans as fluorophore for DNA detection. J. Photochem. Photobiol. B Biol. 2017, 172, 36-41, doi:10.1016/j.jphotobiol.2017.05.014.

149. Soni, H.; Pamidimukkala, P.S. Green synthesis of N, S co-doped carbon quantum dots from triflic acid treated palm shell waste and their application in nitrophenol sensing. Mater. Res. Bull. 2018, 108, 250-254, doi:10.1016/j.materresbull.2018.08.033.

150. Pankaj, A.; Tewari, K.; Singh, S.; Singh, S.P. Waste candle soot derived nitrogen doped carbon dots based fluorescent sensor probe: An efficient and inexpensive route to determine $\mathrm{Hg}(\mathrm{II})$ and $\mathrm{Fe}(\mathrm{III})$ from water. J. Environ. Chem. Eng. 2018, 6, 5561-5569, doi:10.1016/j.jece.2018.08.059.

151. Venkatesan, S.; Jhonsi, M.A.; Kathiravan, A.; Muthupandian, A. Fuel waste to fluorescent carbon dots and its multifarious applications. Sens. Actuators B Chem. 2019, 282, 972-983, doi:10.1016/j.snb.2018.11.144. 
152. Chung, H.K.; Wongso, V.; Sambudi, N.S. Biowaste-derived carbon dots/hydroxyapatite nanocomposite as drug delivery vehicle for acetaminophen. J. Sol-Gel Sci. Technol. 2020, 93, 214-223, doi:10.1007/s10971-019-05141-w.

153. Aruni Abdul Manaf, S.; Hegde, G.; Kumar Mandal, U.; Tin Wui, W.; Roy, P. Functionalized Carbon Nano-scale Drug Delivery Systems From Biowaste Sago Bark For Cancer Cell Imaging. Curr. Drug Deliv. 2017, 14, 1071-1077.

154. Kang, Z.; Liu, Y. Catalytic Applications of Carbon Dots. In Carbon Nanoparticles and Nanostructures; Yang, N., Jiang, X., Pang, D.W., Eds; Springer International Publishing: Berlin/Heidelberg, Germany, 2016; pp. 257-298.

155. Yao, Y.-Y.; Gedda, G.; Girma, W.M.; Yen, C.-L.; Ling, Y.-C.; Chang, J.-Y. Magnetofluorescent Carbon Dots Derived from Crab Shell for Targeted Dual-Modality Bioimaging and Drug Delivery. ACS Appl. Mater. Interfaces 2017, 9, 13887-13899, doi:10.1021/acsami.7b01599.

156. Qu, A.; Xie, H.; Xu, X.; Zhang, Y.; Wen, S.; Cui, Y. High quantum yield graphene quantum dots decorated TiO2 nanotubes for enhancing photocatalytic activity. Appl. Surf. Sci. 2016, 375, 230-241, doi:10.1016/j.apsusc.2016.03.077.

157. Hod, I.; González-Pedro, V.; Tachan, Z.; Fabregat-Santiago, F.; Mora-Sero, I.; Bisquert, J.; Zaban, A. Dye versus Quantum Dots in Sensitized Solar Cells: Participation of Quantum Dot Absorber in the Recombination Process. J. Phys. Chem. Lett. 2011, 2, 30323035, doi:10.1021/jz201417f.

158. Kumar, A.; Vemula, P.K.; Ajayan, P.M.; John, G.C. Silver-nanoparticle-embedded antimicrobial paints based on vegetable oil. Nat. Mater. 2008, 7, 236-241, doi:10.1038/nmat2099.

159. Stepanidenko, E.; Ushakova, E.; Fedorov, A.; Rogach, A. Applications of Carbon Dots in Optoelectronics. Nanomaterials 2021, 11, 364, doi:10.3390/nano11020364.

160. Cappai, A.; Melis, C.; Stagi, L.; Ricci, P.C.; Mocci, F.; Carbonaro, C.M. Insight into the Molecular Model in Carbon Dots through Experimental and Theoretical Analysis of Citrazinic Acid in Aqueous Solution. J. Phys. Chem. C 2021, 125, 4836-4845, doi:10.1021/acs.jpcc.0c10916.

161. Surendran, P.; Lakshmanan, A.; Vinitha, G.; Ramalingam, G.; Rameshkumar, P. Facile preparation of high fluorescent carbon quantum dots from orange waste peels for nonlinear optical applications. Luminescence 2020, 35, 196-202, doi:10.1002/bio.3713.

162. Achilleos, D.S.; Kasap, H.; Reisner, E. Photocatalytic hydrogen generation coupled to pollutant utilisation using carbon dots produced from biomass. Green Chem. 2020, 22, 2831-2839, doi:10.1039/d0gc00318b.

163. Aggarwal, R.; Saini, D.; Singh, B.; Kaushik, J.; Garg, A.K.; Sonkar, S.K. Bitter apple peel derived photoactive carbon dots for the sunlight induced photocatalytic degradation of crystal violet dye. Sol. Energy 2020, 197, 326-331, doi:10.1016/j.solener.2020.01.010.

164. Sarswat, P.K.; Free, M.L. Light emitting diodes based on carbon dots derived from food, beverage, and combustion wastes. Phys. Chem. Chem. Phys. 2015, 17, 27642-27652, doi:10.1039/c5cp04782j.

165. Shabashini, A.; Panja, S.K.; Nandi, G.C. Applications of Carbon Dots (CDs) in Latent Fingerprints Imaging. Chem. Asian J. 2021, 16, 1057-1072, doi:10.1002/asia.202100119.

166. Verhagen, A.; Kelarakis, A. Carbon Dots for Forensic Applications: A Critical Review. Nanomaterials 2020, 10, 1535, doi:10.3390/nano10081535.

167. Fahmi, M.Z.; Sukmayani, W.; Khairunisa, S.Q.; Witaningrum, A.M.; Indriati, D.W.; Matondang, M.Q.Y.; Chang, J.-Y.; Kotaki, T.; Kameoka, M. Design of boronic acid-attributed carbon dots on inhibits HIV-1 entry. RSC Adv. 2016, 6, 92996-93002, doi:10.1039/c6ra21062g.

168. Kotta, S.; Aldawsari, H.M.; Badr-Eldin, S.M.; Alhakamy, N.A.; Nair, A.B.; Deb, P.K. Exploring the Potential of Carbon Dots to Combat COVID-19. Front. Mol. Biosci. 2020, 7, 616575, doi:10.3389/fmolb.2020.616575.

169. Saravanan, A.; Maruthapandi, M.; Das, P.; Luong, J.; Gedanken, A. Green Synthesis of Multifunctional Carbon Dots with Antibacterial Activities. Nanomaterials 2021, 11, 369, doi:10.3390/nano11020369.

170. Park, Y.; Yoo, J.; Lim, B.; Kwon, W.; Rhee, S.-W. Improving the functionality of carbon nanodots: doping and surface functionalization. J. Mater. Chem. A 2016, 4, 11582-11603, doi:10.1039/c6ta04813g.

171. Tuccitto, N.; Riela, L.; Zammataro, A.; Spitaleri, L.; Li-Destri, G.; Sfuncia, G.; Nicotra, G.; Pappalardo, A.; Capizzi, G.; Sfrazzetto, G.T. Functionalized Carbon Nanoparticle-Based Sensors for Chemical Warfare Agents. ACS Appl. Nano Mater. 2020, 3, 8182-8191, doi:10.1021/acsanm.0c01593.

172. Long, C.; Jiang, Z.; Shangguan, J.; Qing, T.; Zhang, P.; Feng, B. Applications of carbon dots in environmental pollution control: A review. Chem. Eng. J. 2021, 406, 126848, doi:10.1016/j.cej.2020.126848.

173. Otis, G.; Bhattacharya, S.; Malka, O.; Kolusheva, S.; Bolel, P.; Porgador, A.; Jelinek, R. Selective Labeling and Growth Inhibition of Pseudomonas aeruginosa by Aminoguanidine Carbon Dots. ACS Infect. Dis. 2019, 5, 292-302.

174. Lin, F.; Bao, Y.-W.; Wu, F.-G. Carbon Dots for Sensing and Killing Microorganisms. C 2019, 5, 33.

175. Alahi, M.E.E.; Mukhopadhyay, S.C. Detection Methodologies for Pathogen and Toxins: A Review. Sensors 2017, $17,1885$.

176. Gao, R.; Zhong, Z.; Gao, X.; Jia, L. Graphene Oxide Quantum Dots Assisted Construction of Fluorescent Aptasensor for Rapid Detection of Pseudomonas aeruginosa in Food Samples. J. Agric. Food Chem. 2018, 66, 10898-10905, doi:10.1021/acs.jafc.8b02164.

177. Travlou, N.A.; Giannakoudakis, D.A.; Algarra, M.; Labella, A.M.; Rodríguez-Castellón, E.; Bandosz, T.J. S- and N-doped carbon quantum dots: Surface chemistry dependent antibacterial activity. Carbon 2018, 135, 104-111, doi:10.1016/j.carbon.2018.04.018.

178. Jijie, R.; Barras, A.; Bouckaert, J.; Dumitrascu, N.; Szunerits, S.; Boukherroub, R. Enhanced antibacterial activity of carbon dots functionalized with ampicillin combined with visible light triggered photodynamic effects. Colloids Surfaces B Biointerfaces 2018, 170, 347-354, doi:10.1016/j.colsurfb.2018.06.040.

179. Shi, B.; Su, Y.; Zhang, L.-L.; Huang, M.; Liu, R.; Zhao, S. Nitrogen and Phosphorus Co-Doped Carbon Nanodots as a Novel Fluorescent Probe for Highly Sensitive Detection of $\mathrm{Fe}^{3+}$ in Human Serum and Living Cells. ACS Appl. Mater. Interfaces 2016, 8, 1071710725, doi:10.1021/acsami.6b01325. 
180. Wang, L.; Hu, C.; Shao, L. The antimicrobial activity of nanoparticles: present situation and prospects for the future. Int. J. Nanomed. 2017, 12, 1227-1249, doi:10.2147/ijn.s121956.

181. Safardoust-Hojaghan, H.; Salavati-Niasari, M.; Amiri, O.; Hassanpour, M. Preparation of highly luminescent nitrogen doped graphene quantum dots and their application as a probe for detection of Staphylococcus aureus and E. coli. J. Mol. Liq. 2017, 241, 1114-1119, doi:10.1016/j.molliq.2017.06.106.

182. Jian, H.-J.; Wu, R.-S.; Lin, T.-Y.; Li, Y.-J.; Lin, H.-J.; Harroun, S.G.; Lai, J.-Y.; Huang, C.-C. Super-Cationic Carbon Quantum Dots Synthesized from Spermidine as an Eye Drop Formulation for Topical Treatment of Bacterial Keratitis. ACS Nano 2017, 11, 67036716, doi:10.1021/acsnano.7b01023.

183. Liu, J.; Lu, S.; Tang, Q.; Zhang, K.; Yu, W.; Sun, H.; Yang, B. One-step hydrothermal synthesis of photoluminescent carbon nanodots with selective antibacterial activity against Porphyromonas gingivalis. Nanoscale 2017, 9, 7135-7142, doi:10.1039/c7nr02128c.

184. Thakur, M.; Pandey, S.; Mewada, A.; Patil, V.; Khade, M.; Goshi, E.; Sharon, M. Antibiotic Conjugated Fluorescent Carbon Dots as a Theranostic Agent for Controlled Drug Release, Bioimaging, and Enhanced Antimicrobial Activity. J. Drug Deliv. 2014, 2014, 19, doi:10.1155/2014/282193.

185. Verma, A.; Shivalkar, S.; Sk, P.; Samanta, S.K.; Sahoo, A.K. Nanocomposite of Ag nanoparticles and catalytic fluorescent carbon dots for synergistic bactericidal activity through enhanced reactive oxygen species generation. Nanotechnology 2020, 31, 405704, doi:10.1088/1361-6528/ab996f.

186. Niu, J.; Gao, H. Synthesis and drug detection performance of nitrogen-doped carbon dots. J. Lumin. 2014, 149, 159-162, doi:10.1016/j.jlumin.2014.01.026.

187. Han, S.; Zhang, H.; Zhang, J.; Xie, Y.; Liu, L.; Wang, H.-X.; Li, X.; Liu, W.; Tang, Y. Fabrication, gradient extraction and surface polarity-dependent photoluminescence of cow milk-derived carbon dots. RSC Adv. 2014, 4, 58084-58089, doi:10.1039/c4ra09520k. 188. Burdușel, A.-C.; Gherasim, O.; Grumezescu, A.M.; Mogoantă, L.; Ficai, A.; Andronescu, E. Biomedical Applications of Silver Nanoparticles: An Up-to-Date Overview. Nanomaterials 2018, 8, 681, doi:10.3390/nano8090681.

189. Salleh, A.; Naomi, R.; Utami, N.D.; Mohammad, A.W.; Mahmoudi, E.; Mustafa, N.; Fauzi, M.B. The Potential of Silver Nanoparticles for Antiviral and Antibacterial Applications: A Mechanism of Action. Nanomaterials 2020, 10, 1566, doi:10.3390/nano10081566. 